Research Article

\title{
Experimental Assessments of Treating Effect on Retaining Walls for Loess Slopes under Long-Term Rainfall
}

\author{
Guodong Liu $\mathbb{D}^{1,2}$ Zhijun Zhou, ${ }^{1}$ Shiqiang $\mathrm{Xu},{ }^{1}$ and Wenjing $\mathrm{Mi}^{2}$ \\ ${ }^{1}$ School of Highway, Chang'an University, Xi'an 710046, China \\ ${ }^{2}$ College of Urban, Rural Planning and Architectural Engineering, Shangluo University, Shangluo 726000, China
}

Correspondence should be addressed to Guodong Liu; 2017021006@chd.edu.cn

Received 7 January 2021; Revised 15 March 2021; Accepted 30 March 2021; Published 15 April 2021

Academic Editor: Pitthaya Jamsawang

Copyright (C) 2021 Guodong Liu et al. This is an open access article distributed under the Creative Commons Attribution License, which permits unrestricted use, distribution, and reproduction in any medium, provided the original work is properly cited.

Failures of treated slope occurring in China are at a continually increasing rate, and the huge number of treated loess slopes is calling for a postevaluation; however, no mature technique is in place. Based on an actual loess slope in Shaanxi Province treated by retaining wall, indoor geotechnical and model tests were conducted, revealing the rainwater infiltration process and pressure variations behind the wall, and the processes were then adopted to perform the postevaluation of the treated slope. The results proposed that effectual measures hence needed to be taken so as to avert rainwater infiltrating along the wall face and back or flowing through the wall body, which can soften the soil of the slope bottom. Although the wet front was developed by the rainfall process, it cannot be used as the boundary between saturated and unsaturated areas. Despite the peculiarly large soil pressure upon the wall back at the top layer, the soil pressure increases to a large value and then decreases with the depth. The model test results and investigation results were used to conduct the postevaluation of the prototype slope, which formed a postevaluation frame relevant to other slope postevaluations.

\section{Introduction}

Loess characterized by large porosity and water sensitivity forms a great number of slopes in the northwest of China, including natural slopes and artificial slopes [1]. Limited by the shortcomings of engineering technology of China in the last century, most of the artificial slopes in northwest China cannot guarantee ample safety after approximately a century of operation, especially for slopes treated by retaining walls. Consequently, the treated loess slopes collapsed generally in northwest China this century, which has caused serious lifethreatening casualties to the adjacent people [2-7]. Thus, the artificially treated loess slopes distributed in northwest China need a remedial approach to prevent them from collapsing. This posed a new researching issue, namely, postevaluation of treated slopes, that differs from safety evaluation in project designing [8-10].

In the postevaluation of slopes, the researcher's focal point is on the operational situation of the project, described by the characterization of the slopes such as the surface cracks, displacements, and adaptations to the environment $[11,12]$. In view of the deficiency of the aforementioned qualitative analysis, some analysts set in motion stress evaluation methods into the slope treatment effect assessment [13]. Apart from their promoting effects to the current field, these developed assessment methods all fell into the limited range of qualitative or semiquantitative evaluation, without considering the long-term rainfall effects. Referring to the postevaluation, this issue must be a long-time operation problem without giving consideration to long-term rainfall [14].

These years, more researchers devoted themselves to the field of slope stability and failure mechanism study under rainfall, involving modelling test [15-20], numerical simulation [21-24], and field monitoring [25-27]. As investigated, slope safety is mostly influenced by rainfall, causing the surface erosion to the slopes by runoff [28-32], weakening the slope soil strength while percolating into the slope body [33-37], and reducing the effective stress in the slope soil while saturating the slope body [38-42]. For the soil 
slope is loose, especially for the loess slopes, the raindrops and the runoff water can easily scour the soil particles on the slope surface, in due course forming gullies and fall-holes in the slopes [43]. To alleviate the scouring by rainwater runoff, the vegetation covering method and geobarrier system were proposed by some scholars, ascertaining that both methods are capable of protecting the soil slopes from rainwater scouring and maintaining the stability of the slopes [44]. Consequently, the suction in the soil contributes significantly to the strength of slope soil. This is a crucial factor in slope stability [45]. As the rainwater percolates into the slopes, mainly for the slope with cracks on the slope surface, the water content of the slope soil increases, inducing the dropping of the suction, even causing the lifting of the groundwater level, which may eventually lead to the collapse of the slope [46]. Additionally, as a positive factor to the frictional strength of the soil, the effective stress favorable to the slope stability decreases with the increase of the pore water pressure in the rainfall process [47]. Evidently, rainfall has been a critical factor in the instability of slopes. In the circumstances of practical engineering, water drainage measures should be the obligatory practice to any project to alleviate the hazards of rainwater percolating.

The most direct and convictive method to study the slope stability (or slope treating effect) and failure mechanism is by model test, taken on by many researchers. Song and Tan [48] made use of the model test to study the influence of different slope surface covering on failure mechanism under intense rainfall. The results indicated that the slope with a bare surface is most prone to failure, with a sudden slide failure of the linear sliding surface. Hojat et al. [49] adopted a laboratory model test to study the exert influence of the rainwater infiltrating process on the slope sliding. As stipulated, the landslide body became unstable when the water saturation exceeded $45 \%$, and the sliding surface was consistent with the interface of different saturation areas. Chueasamat et al. [50] used a $1 \mathrm{~g}$ slope model to investigate the failure mechanism of slopes composed of two different soil layers under different rainfall intensities. It indicated two different types of failures: videlicet surface sliding failure and retrogressive failure. Tohari et al. [51] incorporated the slope model into the study and ascertained that, under the rainfall condition, the localized failure surface is noncircular with nearly saturated water content, while the overall instability area retained unsaturated. The rainwater percolating process in the soil slope was studied by Park and Song [52] who found that the rainwater firstly concentrated at the slope toe forming a saturated zone near the slope toe advanced toward the slope crest. The sliding failure ensues in the saturated area.

From the above, the preceding research studies are mainly attentive to the pre-evaluation of slopes (aiming at design), while some limited amounts of postevaluation researching results are based on rock slopes or without treatment. Taking China's loess slopes into account, there is hardly any research results of this aspect under the rainfall condition. In view of the great number of treated slopes in northwest China operated for a long time, this issue has been a research subject that needed to be commenced urgently.
Employing a model flume in the ongoing research, a retaining wall-treated loess slope model shrunk by 10 times from the prototype was constructed in the laboratory to scrutinize the treating effect of the retaining wall on this slope. Also, the rainwater infiltrating process, pore water varying process, and soil pressure upon the wall back were monitored, which would dispense some illustration to the effects of rainfall on the degradation of the treated loess slope. The sections of this paper below depict the regime of the model test and the results of the test, followed by the treating effect evaluation (postevaluation) incorporating the test results. The formed approach of the treating effect evaluation for retaining wall-treated loess slope can be relevant to other slopes, while the obtained rainwater infiltration and soil pressure variation rules can be adopted to facilitate the design and maintenance of the retaining walltreated slopes.

\section{The Prototype Failure}

The slope prototype is situated in Zhangwan Village, Diantou Town, Huangling County, Yan'an City, Shaanxi Province, as shown in Figure 1. The geographical coordinates of the project are $109^{\circ} 05^{\prime} 46.92^{\prime \prime} \mathrm{E}$ and $35^{\circ} 38^{\prime} 3.55^{\prime \prime} \mathrm{N}$, with an average elevation of $970 \mathrm{~m}$. It consists of a temperate continental monsoon climate, with an annual average temperature of $9.4^{\circ} \mathrm{C}$ and an annual utmost maximum temperature of $39.4^{\circ} \mathrm{C}$. The average annual precipitation of Huangling County is approximately $690.2 \mathrm{~mm}$, briefly concentrated in July, August, and September.

Located on the loess plateau, the current project is a loess slope treated by a stone gravity retaining wall with an uphill road on the crest. That is, the soils behind the retaining wall are wholly loess formed in the late Pleistocene epoch. As Figure 2(a) shows, the height of the slope is $8.6 \mathrm{~m}$, the back of the retaining wall is vertical, the slope of the retaining wall surface is $70^{\circ}$, and the width of the retaining wall top is $55 \mathrm{~cm}$. From this, the retaining wall width at the height of the slope toe is $3185 \mathrm{~cm}$.

From field investigation and datum collection, this project was built around the year 2012, having been operated for virtually 5 years when the field investigation was performed. After a long period of operation degrading by the rainfall, the retaining wall was found extruded in the middle height of the slope (see Figure 2(b)). To make the postevaluation for this project by modelling test, the simulated time must be 5 years depending on the actual project operation time frame. Pursuant to the similarity theory, the test time can be shortened 100 times, and thus, this model test can be completed in a more tolerable period of time.

\section{Methodology and Test Model}

3.1. Test Device. The rainfall test was conducted in the Soil Mechanics Laboratory of Shangluo University, China. A box of $1 \mathrm{~m}$ in width, $2.5 \mathrm{~m}$ in length, and $1.8 \mathrm{~m}$ in height was adopted in the experiment (see Figure 3(a)). The left and right side walls of the box were made from organic glass, making the displacement of the slope soil and the wetting front visible. The 
base and the back wall of the box were made from plank, and the front of the flume was blocked by a plank of $30 \mathrm{~cm}$ height while the upper plank of the front could be removed to let slope surface unrestrained. To vent the rainwater infiltrated into the slope, holes were drilled in the lower $30 \mathrm{~cm}$ high front plank.

A frame made from steel pipes with holes of $1 \mathrm{~mm}$ in diameter was used as a rainfall simulator with the rainfall intensity controlled by the valve connected to the water pipe (see Figure 3(b)). Prior to the rainfall, the rainfall intensity must be calibrated to the desired values, which were measured by a beaker and a measuring cylinder.

3.2. Test Model. The test model corresponded fully to the prototype characteristics of the slope in Zhangwan Village, Diantou Town, Huangling County, Yan'an City, Shaanxi Province, as illustrated in Figure 1. The scale of the model was $1: 10$, and thus, the model height was $0.86 \mathrm{~m}$, the length of the model was $2.5 \mathrm{~m}$ consistent with the length of the model box, while the front $1.08 \mathrm{~m}$ was just $30 \mathrm{~cm}$ thick and horizontal. The retaining wall was constructed from stones and mortar with a slope of $70^{\circ}$ also consistent with the prototype. Shrunk by 10 times from the prototype, the width of the model wall top was $5.5 \mathrm{~cm}$ and the width of the model wall bottom was $17 \mathrm{~cm}$. The detailed dimensions of the test model are shown in Figure 4.

The slope prototype was firstly sampled as undisturbed samples, and the density, water content, grain size distribution, permeability, and shear strength of which were determined by indoor experiments. Dependently, the model material was the same loess procured from the project prototype site. The model was constructed by stratified compaction. To control the mode slope soil density and water content, the mass of each layer of $10 \mathrm{~cm}$ thick was weighed and the model soil was prepared to certain water content in advance. The retaining wall was constructed synchronously with the slope soil.

As Figure 5 illustrates, the model construction process is considerably complicated and can be delineated as follows:

(1) The M5 mortar and stone (average diameter $\approx 15 \mathrm{~cm}$ ) were prepared and were used to build the retaining wall. As every $10 \mathrm{~cm}$ high wall was built, a form was adopted to support the wall against falling.

(2) Synchronously, the procured loess was prepared with precise water content as the prototype $(\omega=17.4 \%)$ and packed into the model box with a certain quantity as a layer, and then each layer was compacted to a thickness of $10 \mathrm{~cm}$ to control the density of the slope model.

(3) Steps 1 and 2 were repeated until the slope was built to the predetermined height.

(4) In the model construction process, the pore water pressure sensors and soil pressure sensors were buried in the designed position. As the model construction process was over, the model was left to stand for 2 days until the mortar solidified

(5) Lastly, the displacement measuring positions were marked on the wall face by a mark pen.
3.3. Model Materials and Similarity Relation. As stated before, the same loess of the prototype slope was procured to construct the slope model. Thus, the density, water content, permeability, and other mechanical parameters of the model material were consistent with the prototype. All the relevant parameters are tabulated in Table 1. By reason of concise, the retaining wall material was also set the same as the prototype, in spite of the stone diameter difference.

It should be taken into account that all the soil properties were obtained from indoor tests. The density of the model soil was measured by a ring knife test: the prototype loess was sampled as ring specimens and weighed by electronic scales. The density of the loess was the ratio of the specimen mass to the volume of the specimen in the ring knife. The water content of the loess was determined by the drying method: a precise mass of the loess was weighed before being dried by an oven and after it was dried for 8 hours at $105 \sim 110^{\circ} \mathrm{C}$. The water content could be derived as the ratio of the water mass, which was in this case the loess mass lost in the drying process, to the loess mass after dried. The permeability coefficient was determined by the variable head permeability test: the loess specimen was installed into the penetration container and sealed to prevent the leakage of water. Then, the variable head device was used to saturate the specimen. Thereafter, the variable head pipe was filled with water to reach a certain water head. The inlet of the penetration container was opened, when the water started to flow out the outlet and started to record the different water heads in the variable head pipe and the corresponding time. Then, the permeability coefficient of the loess could be calculated as follows:

$$
k_{T}=2.3 \frac{a L}{A\left(t_{2}-t_{1}\right)} \log \frac{H_{1}}{H_{2}} .
$$

Here, $a$ is the section area of the variable head pipe, $L$ is the height of the specimen, $t 1$ and $t 2$ are the starting time and the end time of the water head varying, respectively, and $H 1$ and $H 2$ are the starting water head and the end water head corresponding to $t 1$ and $t 2$. It should be noted that the calculated permeability coefficient from equation (1) needs to be rectified according to the actual temperature. The compression modulus was determined from the standard consolidation test: the cylindrical specimens were installed into the osmotic pressure container before different levels of pressure were applied. Then the different specimen heights at corresponding pressure levels were recorded when the compression was stable, from which the specimen height decrements of different pressure levels were derived. The varying void ratios derived from the initial density of the specimen, the specific gravity of soil particles, the initial water content, and the specimen height decrements at different pressure levels were used to calculate the compression modulus. The internal friction angle and cohesion were determined by quick shear test: the ring specimens were installed into the direct shearing apparatus followed by the application of different vertical pressures and quick shearing process (shear rate $=0.8 \mathrm{~mm} / \mathrm{min}$ ). The shear stresses at shear failure measured by the measuring ring were 


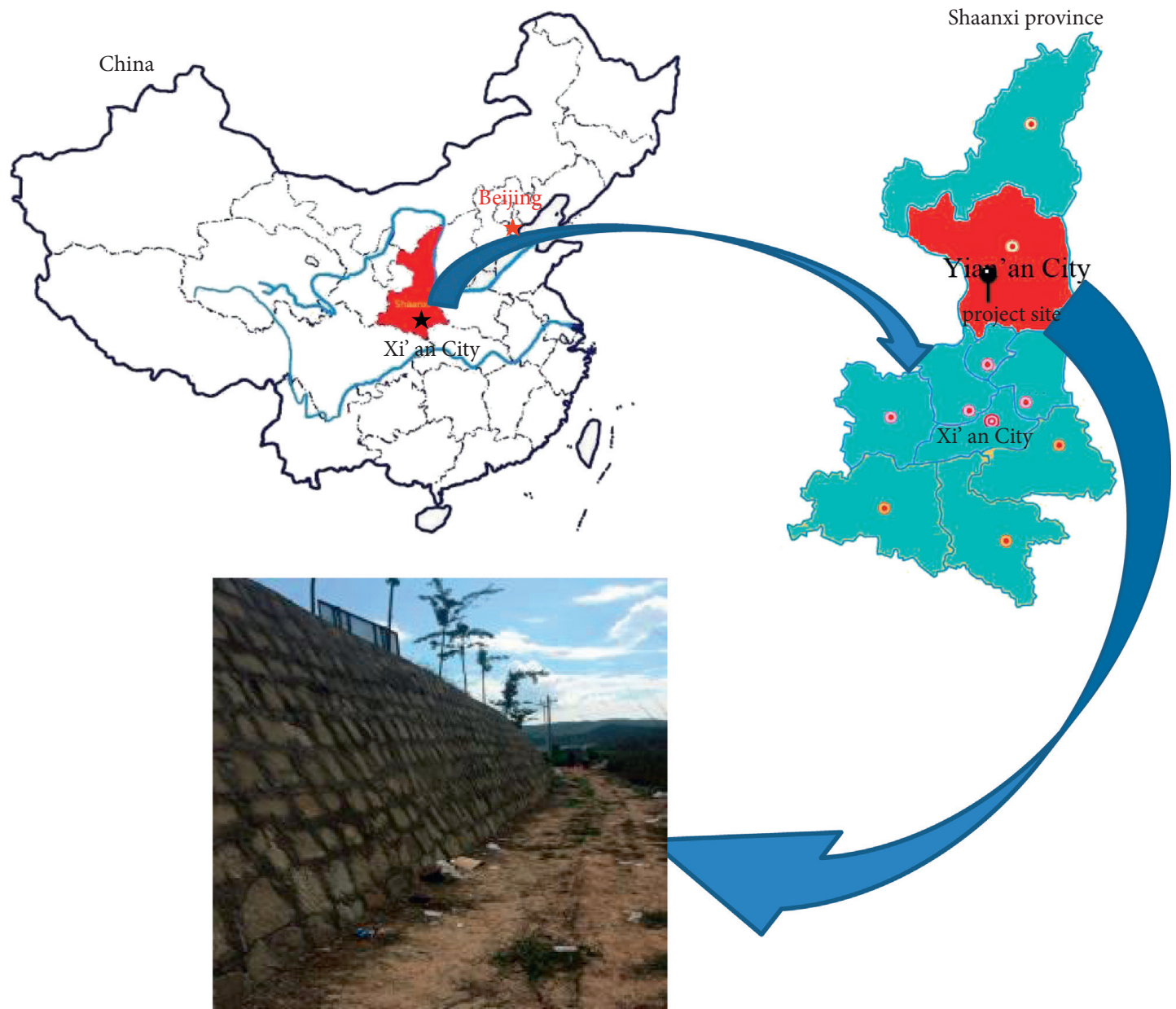

FIGURE 1: Slope prototype location in China.
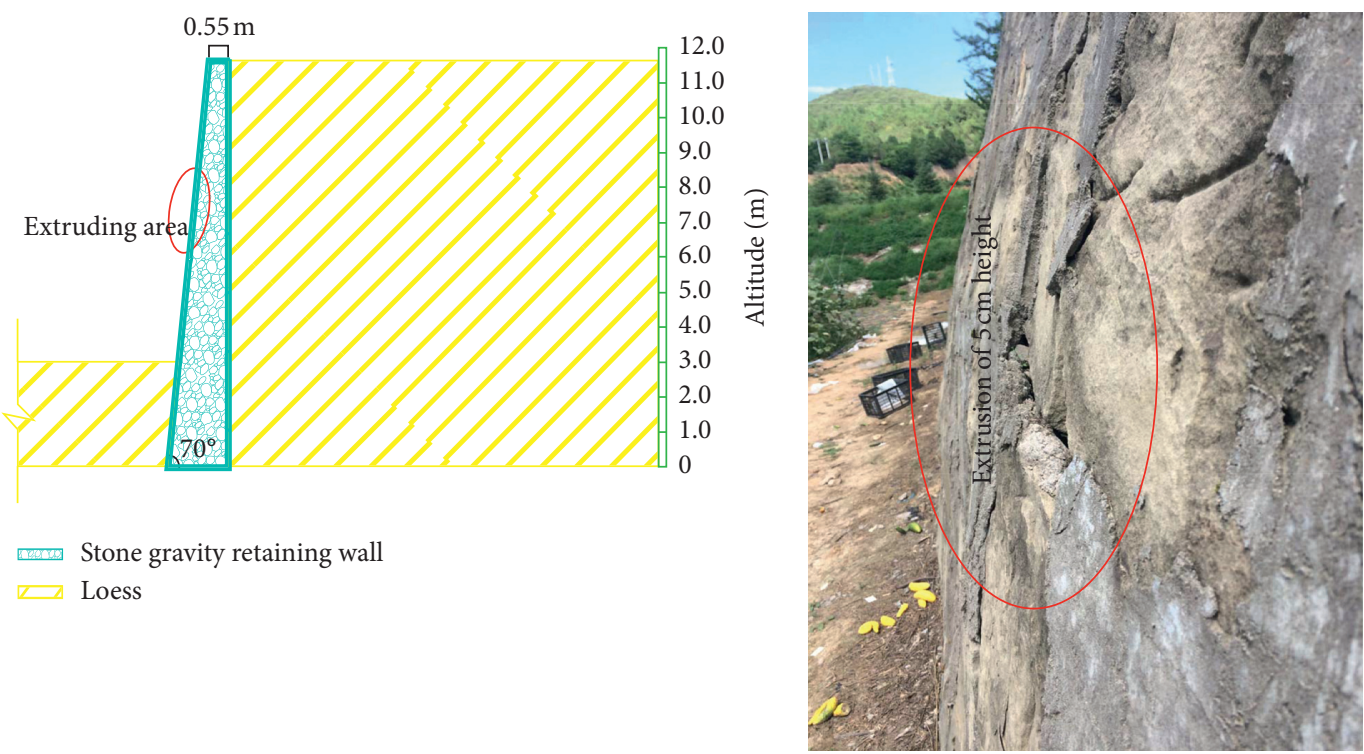

(a)

(b)

FIgure 2: The slope prototype section with extrusion. (a) Prototype section. (b) Retaining wall extrusion. 


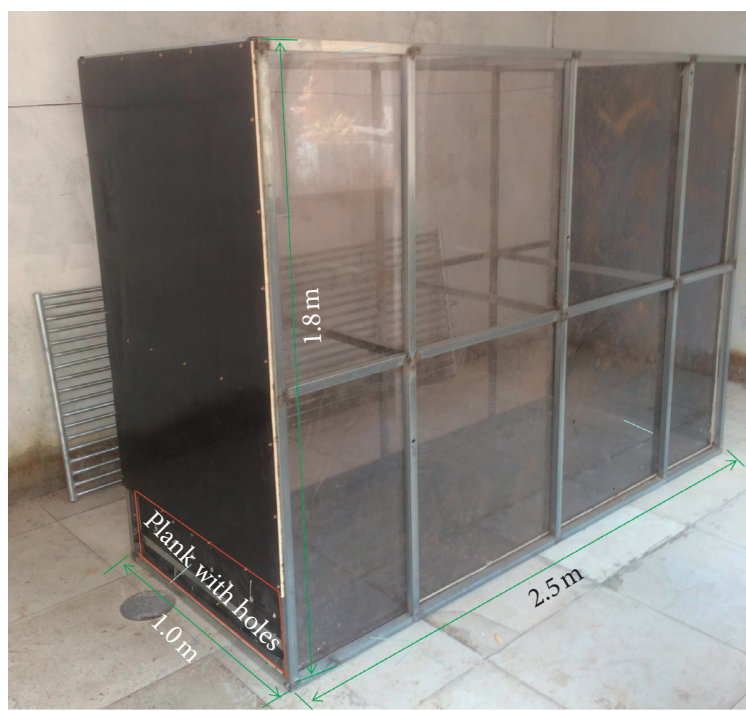

(a)

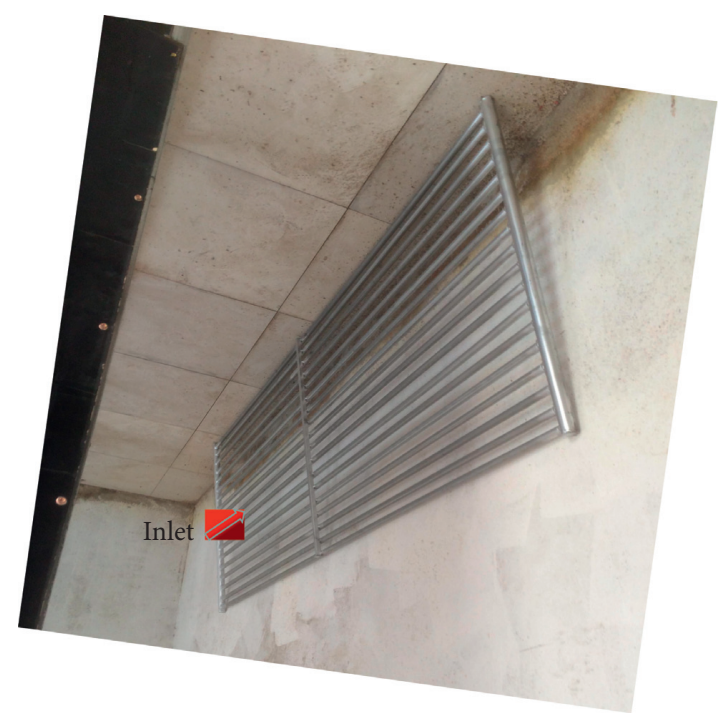

(b)

Figure 3: (a) Model test box and (b) rainfall simulator.

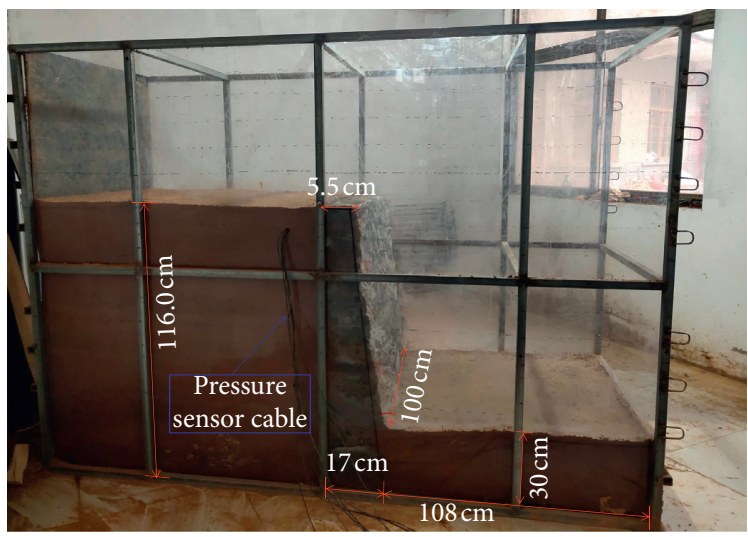

Figure 4: Slope model.

defined as the shear strengths, which can be depicted as a line fitting the shear strength points in the coordinate system of $\tau-\sigma$. The intercept of the line with $\tau$ axis was the $c$ value, and the angle between the line and the $\sigma$ axis was the internal friction angle. The above parameters could be used to characterize the model soil material. To be more persuasive, the indoor tests are illustrated in Figure 6.

Based on $\pi$ theorem $[53,54]$, the similarity criterion was derived through dimensional analysis. For the complexity of the model, it was difficult to meet the similarities of all parameters. Thus, we selected the primary parameters as fundamental dimensions according to the test purpose and model characteristics. Herein, the geometric length, density, and gravity acceleration were selected as the fundamental dimensions. All the similar constants in this test are tabulated in Table 2.

It is noteworthy that the rainfall duration similarity constant was not derived from $\pi$ theorem, rather from a calculation based on Terzaghi's consolidation theorem [55].
This method has been validated by Li [56] in his doctoral dissertation and was adopted by Zhao [57] and Tang [58] in the research of slope under rainfall. Although the geometric dimension of the model was different from the prototype, in the rainfall process, the consolidation degree of the model should be the same as the prototype. According to Terzaghi's consolidation theorem, the consolidation of the slope soil can be described as

$$
U=1-\beta \cdot e^{-\lambda \cdot T_{V}},
$$

where $\beta$ and $\lambda$ are two mathematical constants invariable with other factors and $T_{v}$ is the time factor related to the consolidated time. Thus, the consolidation degree is solely affected by consolidation time.

Reasonably, $\beta$ values of the model and the prototype are the same, while $\lambda$ values of the model and the prototype are also the same. Therefore, upon the same consolidation degree, their time factors are identical, i.e., 

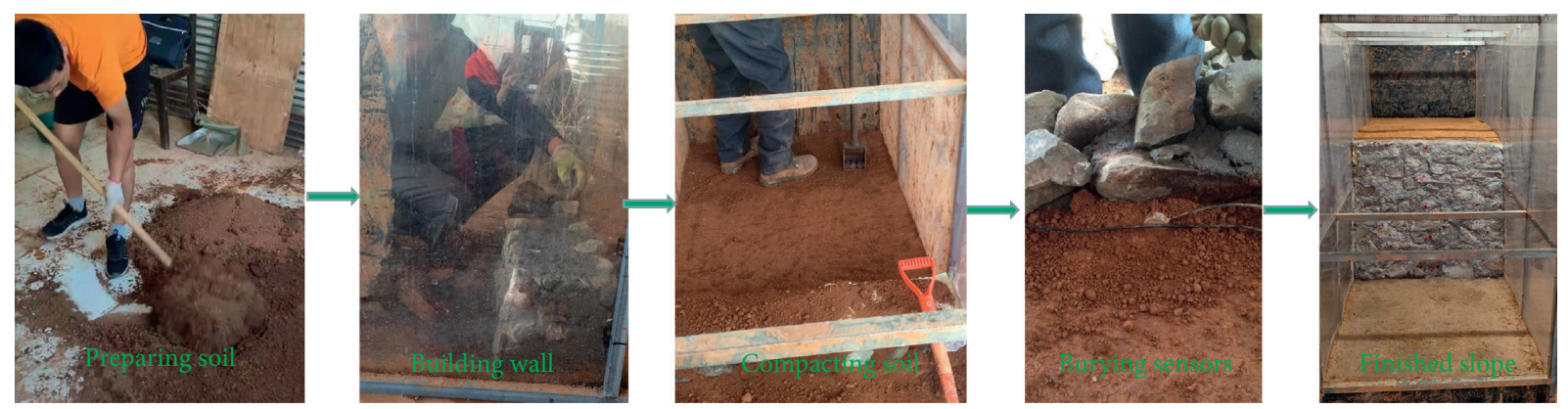

FIGURE 5: Slope model construction process.

TABLE 1: Key properties of the model soil material.

\begin{tabular}{lc}
\hline Parameters & Value \\
\hline Density $\left(\mathrm{g} / \mathrm{cm}^{3}\right)$ & 1.42 \\
Water content $(\%)$ & 17.4 \\
Permeability coefficient $(\mathrm{cm} / \mathrm{s})$ & $5.4 \times 10^{-4}$ \\
Compression modulus $(\mathrm{MPa})$ & 5.58 \\
Internal friction angle $\left(^{\circ}\right)$ & 27.0 \\
Cohesion $(\mathrm{kPa})$ & 15.0 \\
\hline
\end{tabular}

$$
T_{V_{p}}=T_{V_{m}}
$$

Here, $T_{V p}$ is the time factor of the prototype and $T_{V m}$ is the time factor of the model. The relation between them and the consolidation time can be defined as follows.

$$
\begin{aligned}
& t_{p}=\left(\frac{H_{p}^{2}}{C_{V}}\right) T_{V_{p}}, \\
& t_{m}=\left(\frac{H_{m}^{2}}{C_{V}}\right) T_{V_{m}} .
\end{aligned}
$$

Here, $t_{p}$ and $t_{m}$ are the consolidation time of the prototype and the model, respectively; $H_{p}$ and $H_{m}$ are the dimensions of the prototype and the model, respectively; and $C_{v}$ is the identical consolidation coefficient of the prototype and the model. Consequently, the similarity ratio of rainfall duration can be derived as follows:

$$
C_{t}=\frac{t_{p}}{t_{m}}=\frac{H_{p}^{2}}{H_{m}^{2}}=C_{L}^{2} .
$$

In this study, $C_{L}$ is equal to 10 , inducing $C_{t}$ equaled to 100. In other words, the test duration was shortened by 100 times allowing the experiment to be finished in an acceptable period. While field investigating, the project had been operated for approximately 5 years, thus leading to an experimental period of 0.05 years in this study.

3.4. Measuring System and Rainfall Scheme. A total of 5 pore water pressure sensors and 5 soil pressure sensors were used in the experiment. As we were just concerned about the pressures on the wall back, the pressure sensors were distributed along the wall back as illustrated in Figure 7. The pore water pressure sensor U1 was buried at a depth of
$20 \mathrm{~cm}$, while the buried depth of U2, U3, U4, and U5 was increasing $20 \mathrm{~cm}$ sequentially. Understandably, the soil pressure sensors P1, P2, P3, P4, and P5 were buried at identical depths as $\mathrm{U} 1, \mathrm{U} 2, \mathrm{U} 3, \mathrm{U} 4$, and $\mathrm{U} 5$, respectively, to be meaningful. The pressure sensors were connected a strainometer, which converted the pressures into digital signals and sent them to the computer for storage. It should be noted that the pore pressure sensor needs to be soaked in water for over 8 hours for discharging the air in it, or it would affect the measuring accuracy. Although the experiment simulated a planar issue, the pore water pressure sensors and soil pressure sensors should be located near the axial plane of the model producing more reliable data.

To measure the displacements of representative points, 5 key points were marked by a mark pen on the retaining wall face, which are also illustrated in Figure 7 as S1, S2, S3, S4, and S5 sequentially. S1 was located on the shoulder of the wall, while S2 was located on the wall face with a vertical distance of $20 \mathrm{~cm}$ from S1, and S3, S4, and S5 were also positioned on the wall face with a vertical distance increment of $20 \mathrm{~cm}$ sequentially. Visibly, S2, S3, S4, and S5 were at the same elevations as $\mathrm{P} 1, \mathrm{P} 2, \mathrm{P} 3$, and $\mathrm{P} 4$, respectively. The displacements of the 5 points were derived from the differences of distances before and during rainfall, which were measured by a laser rangefinder constantly seated in a fixed position. The accuracy of this laser rangefinder is up to $0.01 \mathrm{~mm}$ which could satisfy the measuring requirement without any doubt. Conveniently, the laser rangefinder was also connected to the computer to display the distance values.

To capture the deformation process of the retaining wall and the rainwater penetrating process in the slope, a portable camera was adopted to take photos from the front as well as the sides of the model at constant intervals.

As aforementioned, the annual precipitation of Huangling County is approximately $690.2 \mathrm{~mm}$, mainly 


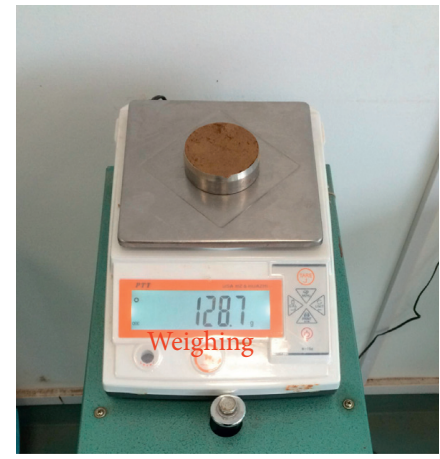

(a)

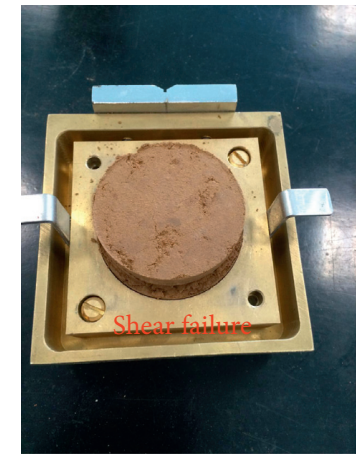

(b)

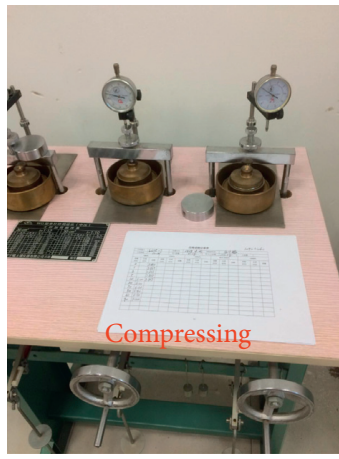

(c)

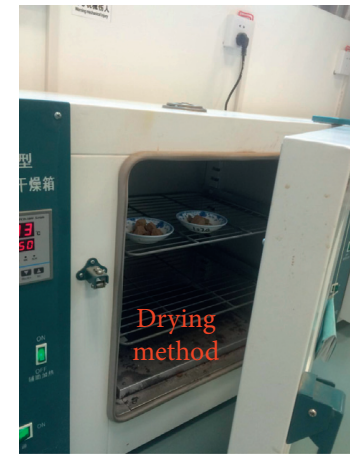

(d)

Figure 6: Photos of indoor geotechnical tests. (a) Density test. (b) Direct shear test. (c) Compression test. (d) Water content test.

TABLE 2: Similarity ratios of the test model.

\begin{tabular}{lcc}
\hline Parameters & Similarity relation & Similarity constant \\
\hline Geometric dimension $(L)$ & $C_{L}$ & 10 \\
Density $(\rho)$ & $C_{\rho}$ & 1 \\
Gravity acceleration $(g)$ & $C_{g}$ & 1 \\
Stress $(\sigma)$ & $C_{\sigma}=C_{\rho} C_{g} C_{L}$ & 10 \\
Strain $(\varepsilon)$ & $C_{\varepsilon}=1$ & 1 \\
Displacement $(s)$ & $C_{s}=C_{L}$ & 10 \\
Cohesion $(C)$ & $C_{C}=C_{\rho} C_{g} C_{L}$ & 10 \\
Internal friction angle $(\varphi)$ & $C_{\varphi}=1$ & 1 \\
Rainfall intensity $\left(C_{q}\right)$ & $C_{q}=C_{\rho}^{0} C_{g}^{0.5} C_{L}^{0.5}$ & $\sqrt{10}$ \\
\hline
\end{tabular}

concentrated in July, August, and September. In this study, we assumed the total annual precipitation distributed in the above three months, with every month consisting of a onetime rainfall lasting 2 hours. After the rainfall, the slope was remained undisturbed for the remaining time of the month. Thus, the 2-hour rainfall intensity was constantly $115.03 \mathrm{~mm} / \mathrm{h}$. The rainfall intensity in the model test could be derived from dividing 115.03 by the similarity constant of $\sqrt{10}$, resulting in the model test rainfall intensity value of about $36.38 \mathrm{~mm} / \mathrm{h}$. More importantly, the total test period could be derived from dividing 5 years by the similarity constant of 100 (see equation (5)), deducing a value of 0.05 years, i.e., 18 days, while the undisturbed intervals between the 3 times of model test rainfall could be derived from dividing 30 days by the similarity constant of 100 then subtracting 2 hours, deducing a period of 5.2 hours. The detailed rainfall scheme of a year is presented in Table 3, which could be repeated 5 times to simulate 5 years of rainfall. below:

Generally, the experimental process followed the steps

(1) The initial values of the pressure sensors were measured before they were buried as the building of the model

(2) After the model was built, the sensor cables were connected to the strainometer which was connected to a computer to capture the pressure data. Simultaneously, the laser rangefinder was fixed at a position and connected to the computer to get the distances between the position and the displacement points (S1, S2, S3, S4, and S5), thus deriving the displacements of the 5 points.

(3) The rainfall intensity of the rainfall simulator was calibrated to the value of $36.38 \mathrm{~mm} / \mathrm{h}$ and then acted on the model slope surface as the pressure capturing program started.

(4) Following the steps of Table 3, the rainfall process was progressed while the pressure values were captured by the program and the rainwater infiltration process was captured by the camera from the front and sides.

\section{Rainwater Infiltration Characteristics}

Slope soil can be saturated by rainwater infiltration, thus increasing the pore water pressure or lessening the suction in the slope body, which significantly affects the slope stability. For retaining wall-treated slopes, the infiltrated rainwater would reduce the internal friction angle of the slope soil, thus causing the significant increment of active earth pressure on the wall back which is adverse to the treating project. Additionally, the infiltrated rainwater accumulated behind the wall, causing the large water pressure on the wall back which is adverse to the stability of the project. Some scholars took the influence of rainfall on the slope stability into account and made discoveries that the rainfall was the most significant factor controlling the stability of slopes and the rainwater infiltrating process dominates the deforming 
process of slopes $[48,50]$. In this study, the two side walls of the model box were made of transparent organic glass. Thus, the rainwater penetration process could be captured by the cameras from the sides.

\subsection{Rainwater Infiltration in front of the Wall. Figure 8} presents the wetting front advancement as the rainwater penetrates in front of the retaining wall in the first year of rainfall. Owing to the fact that the loess in front of the retaining wall was completely wet 5.2 hours after the first rainfall of the first year, the wetting process of the loess in front of the wall subsequent was not visible and consequently not presented here. It is crystal clear that the rainwater preferentially penetrates along the interface between the retaining wall and the front loess. That may be due to the insufficient connection between the loess and the retaining wall face, which could be aggravated, causing the erosion effect of the rainwater or the displacement of the wall. Propelled by the matric suction of the loess, the infiltrated rainwater migrated forward, causing the wet range of the front loess to expand. When the first rainfall of the first year lasted for 20 minutes, the length of the wet range in front of the retaining wall was approximately $25 \mathrm{~cm}$. As the rainfall continued for 60 minutes, the wet range in front of the retaining wall approached $40 \mathrm{~cm}$ length which approximated $51 \mathrm{~cm}$ when the rainfall lasted for $120 \mathrm{~min}$ utes. Lastly, the rainwater completely wet the loess in front of the wall 5.2 hours after the first rainfall of the first year. Consequently, we could therefore derive that, during the rainfall, the horizontal expanding rate of the wetting front in front of the retaining wall was approximately $2.08 \times 10^{-2} \mathrm{~cm} /$ $s$ which gradually decreased to $3.06 \times 10^{-3} \mathrm{~cm} / \mathrm{s}$ when the rainfall conducted for 120 minutes. However, the wetting front expanding rate in front of the wall after the rainfall was approximately $3.04 \times 10^{-4} \mathrm{~cm} / \mathrm{s}$, close to the saturation permeability coefficient of the loess (see Table 1), possibly indicating the saturated status of the soil in front of the wall. Different from the permeating law of unsaturated soil, as the migration of rainwater progressed, the matrix potential of the soil decreased, thus leading to a decrease in the migration rate of rainwater.

From the wetting front advancing process, it can be deduced that although the rainwater accumulated upon the surface of the front loess, the wet area expanding process in front of the retaining wall was mainly dominated by the rainwater penetrated along the interface between the retaining wall and the front loess. That should be attributed to the larger horizontal permeability caused by the layered filling of the slope while the impedance of the interface between the soil layers hinders the rainwater infiltrating vertically. Additionally, after the rainfall, the wetting area kept expanding which was induced by the suction of the loess, causing the dry area to narrow into a dot and disappear lastly (see Figure 8(e)). Consequently, we can infer that measures to avert the rainwater to penetrate along the interface between the retaining wall and the front loess can be effective and efficient ways to alleviate the softening of the front loess, thus preventing the disruption of the wall.
4.2. Rainwater Infiltration behind the Wall. Figures 9 and 10 present the wetting front advancement as the rainwater penetrates behind the retaining wall. It was observed that the loess behind the retaining wall was almost completely wet 70 hours after the third rainfall of the second year, and thus, the rainwater infiltration process subsequent was not visible and not presented here. It is clear that the rainwater preferentially penetrated along the interface between the retaining wall back and the loess likely due to the same reason as the rainwater penetration in front of the wall, while a considerable amount of rainwater flowed through the pores of the retaining wall body and accumulated at the wall back especially the wall heel. Propelled by the matric suction of the loess, the infiltrated rainwater migrated backward, causing the wet range of the back loess to expand. As the rainwater flowed down along the wall back, most of the penetration rainwater accumulated around the wall heel, and the wet range of the model bottom expanded much quicker than that of the upper part.

Within the first year during the beginning of the first rainfall, the rainwater penetrated the retaining wall pores and accumulated at the wall back, inducing the discontinuous wet area behind the wall. Presumably, this discontinuity is the result of the discontinuous pore in the retaining wall which inlets rainwater independently forming wet areas behind the wall. As the rainfall process advanced, more and more rainwater penetrates the wall leading the wet areas behind the retaining wall to gradually integrate. Because the rainwater mainly concentrated at the foot of the slope, the rainwater penetrated the wall bottom was more than that penetrated the upper part, thus causing the wider wet area at the wall heel. Thus, the wet area behind the retaining wall showed trapezoidal distribution during the first rainfall of the first year. When the first rainfall of the first year was conducted for 120 minutes, the width of the wet trapezoid top was about $11 \mathrm{~cm}$ and the width of the bottom of the wet trapezoid was about $31 \mathrm{~cm}$. Approximately the rainwater horizontal infiltration rate in the loess at the retaining wall heel was $4.3 \times 10^{-3} \mathrm{~cm} / \mathrm{s}$. Meanwhile, the vertical infiltration rate of the rainwater at the slope crest showed uniform distribution. When the first rainfall of the first year was conducted for 120 minutes, the rainwater infiltration depth at the slope crest was about $12.5 \mathrm{~cm}$, deriving a vertical infiltration rate of about $1.74 \times 10^{-3} \mathrm{~cm} / \mathrm{s}$. By comparison, the horizontal infiltration rate was clearly higher than the vertical infiltration rate, which is consistent with the conclusion of Gvirtzman [59]. 5.2 hours after the first rainfall of the first year, the $30 \mathrm{~cm}$ thick loess of the model bottom was wet, and the upper wet area showed rectangular distribution, which was caused by the horizontal migration of the more rainwater accumulated at the heel of the wall. Therefore, we can infer that rainwater is more prone to accumulate at the retaining wall heel, which can degrade the strength of the soil behind the wall, thus clearly affecting the stability of the retaining wall. If effective measures are adopted to prevent the rainwater to penetrate the wall body, especially the wall bottom, the retaining wall can more effectively protect the slope for a much longer time.

Visibly, the wetting front was clear just after the rainfall (see Figure 9(e)), but obscure 5.2 hours later (see Figure 9(f)) with the expansion of the wet area causing a decrease in the water 


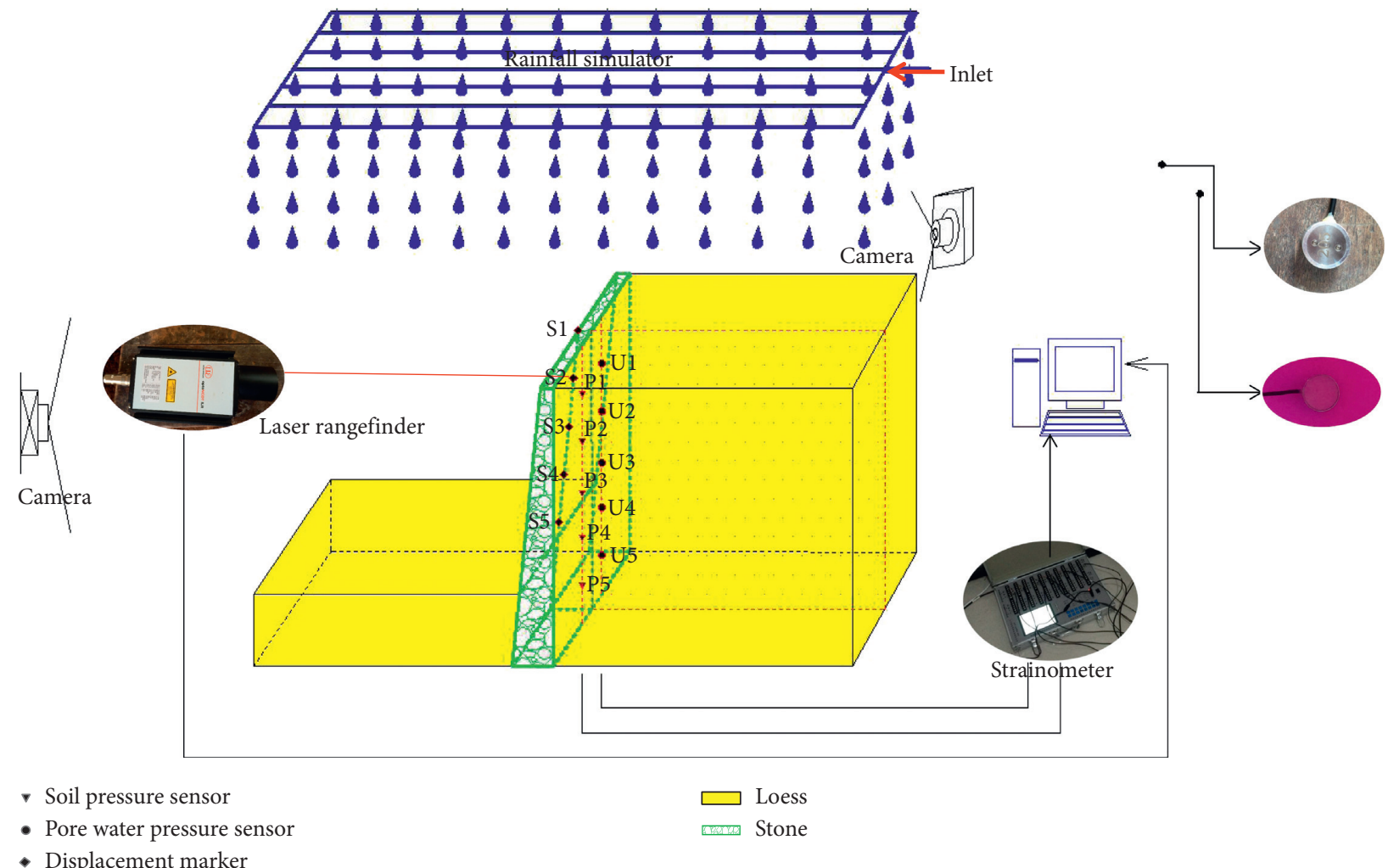

FIGURE 7: Full dimensions of model slope and layout of measurement points.

TABLE 3: The rainfall scheme.

\begin{tabular}{lccc}
\hline Simulating time & Actual time & Rainfall start & Rainfall end \\
\hline $0 \mathrm{~h}$ & $0 \mathrm{~h}$ & Yes & Res \\
$2 \mathrm{~h}$ & $2 \mathrm{~h}$ & & Yes \\
$7.2 \mathrm{~h}$ & $30 \mathrm{~d}$ & & Yes \\
$7.2 \mathrm{~h}+2 \mathrm{~h}$ & $30 \mathrm{~d}+2 \mathrm{~h}$ & Yes & Yes \\
$14.4 \mathrm{~h}$ & $60 \mathrm{~d}$ & & Yes \\
$14.4 \mathrm{~h}+2 \mathrm{~h}$ & $60 \mathrm{~d}+2 \mathrm{~h}$ & & Yes \\
$21.6 \mathrm{~h}$ & $90 \mathrm{~d}$ & & Yes \\
$28.8 \mathrm{~h}$ & $120 \mathrm{~d}$ & & Yes \\
$36 \mathrm{~h}$ & $150 \mathrm{~d}$ & & Yes \\
$43.2 \mathrm{~h}$ & $180 \mathrm{~d}$ & & Yes \\
$50.4 \mathrm{~h}$ & $210 \mathrm{~d}$ & & Yes \\
$57.6 \mathrm{~h}$ & $240 \mathrm{~d}$ & & Yes \\
$64.8 \mathrm{~h}$ & $270 \mathrm{~d}$ & & Yes \\
$72 \mathrm{~h}$ & $300 \mathrm{~d}$ & & Yes \\
$79.2 \mathrm{~h}$ & $330 \mathrm{~d}$ & & Yes \\
$86.4 \mathrm{~h}$ & $360 \mathrm{~d}$ & & Yes \\
\hline
\end{tabular}

content in the wet area. As seen, the width of the wet rectangle behind the retaining wall was about $27.5 \mathrm{~cm}$ when the second rainfall of the first year was conducted for 120 minutes but was $34 \mathrm{~cm} 5.2$ hours later. With the advancing of the rainfall thereafter, the wet rectangle behind the retaining wall expanded continuously and the wet area at the slope crest developed downward, in due course took up the whole slope body (see Figure $10(d)$ ). However, we can infer that the wet area behind the retaining wall could not represent the saturated area because the water in this area was distributed by the matric suctions. It means the slope soils did not get other water from outside to fill the soil pores, and thus, the visible wet area developed was inferred not saturated.

\section{Pressure Variations of the Model Slope}

The retaining wall stability is directly correlated with the pressures upon the wall back, inclusive of the soil pressure and the pore water pressure. Theoretically, in the rainfall process, the soil pressure and the pore water pressure upon the wall back to some extent increase. In a case where the increment of the pressure exceeds the limit, the wall may as a result extrude 


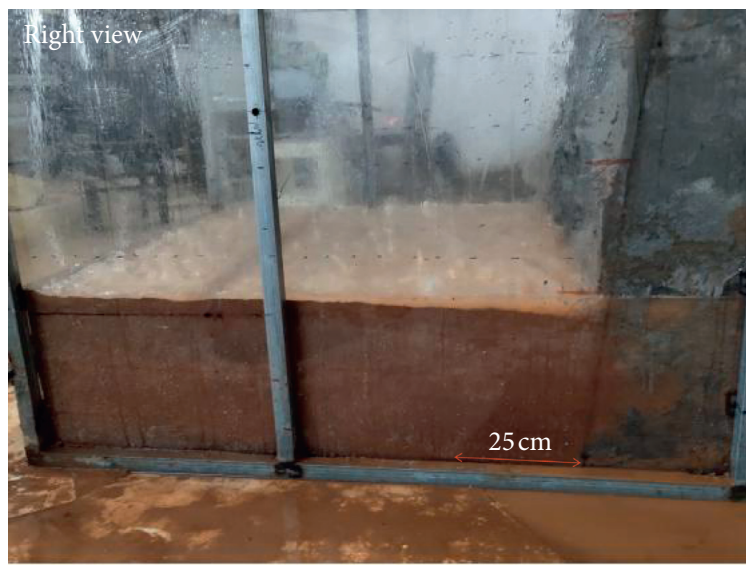

(a)

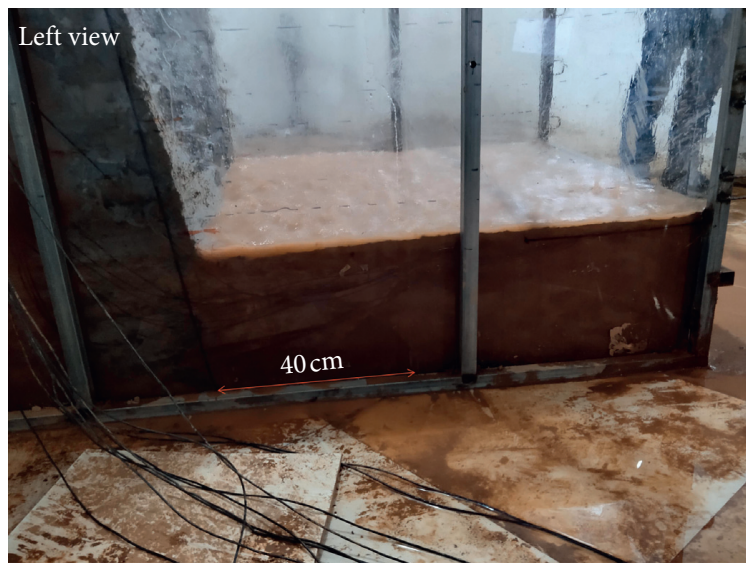

(c)

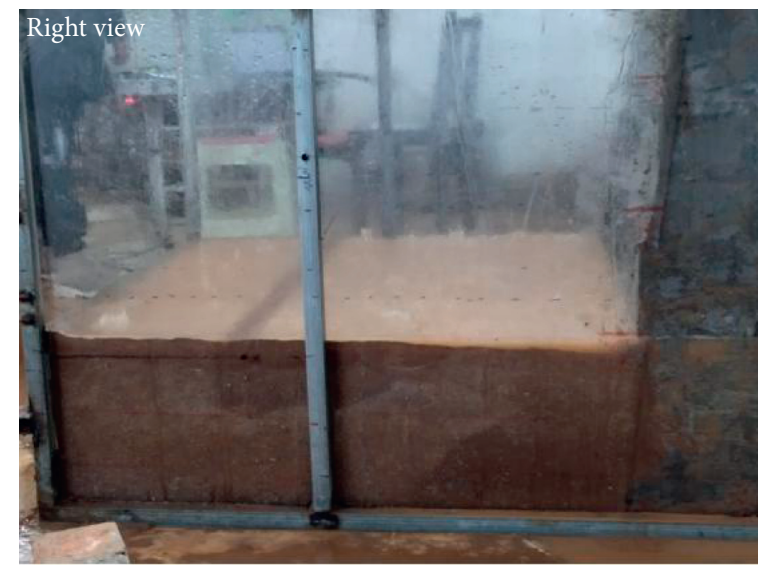

(b)

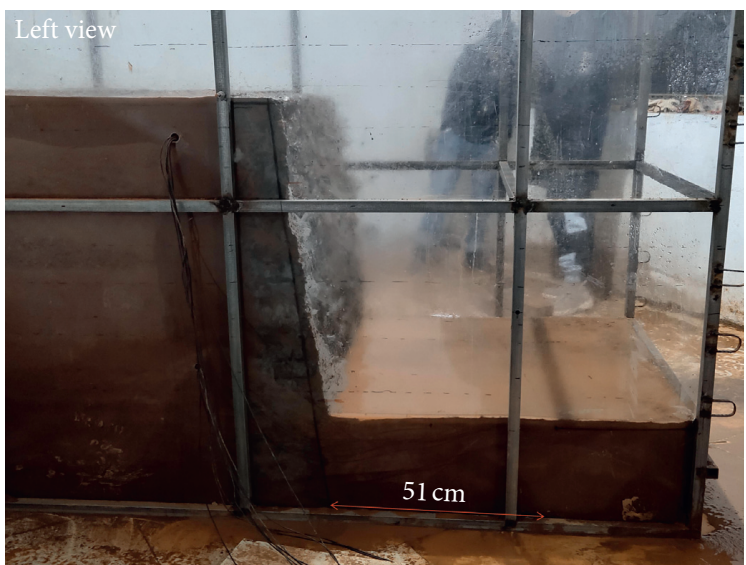

(d)

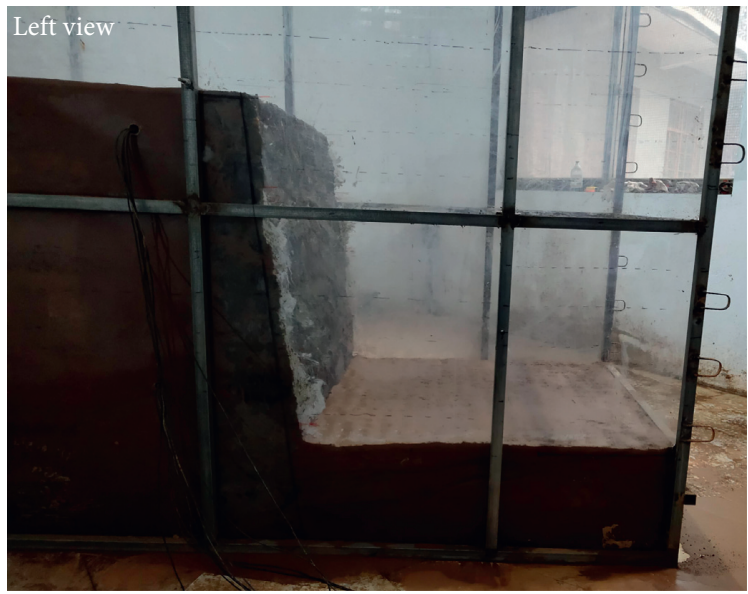

(e)

FIGURE 8: Rainwater infiltration in front of the retaining wall within the first year. (a) First rainfall lasted for 20 minutes. (b) First rainfall lasted for 45 minutes. (c) First rainfall lasted for 60 minutes. (d) First rainfall lasted for 120 minutes. (e) 5.2 hours after the first rainfall.

or incline, indicating the instability of the wall [60]. In this study, before the start of the rainfall, different pressure coefficients depending on the descriptions of the sensor were set in the capturing program. In accordance with this, the capturing program can automatically convert the signals sent by the strainometer into pressure, from which the actual pressure can be procured by subtracting the initial pressure values.
5.1. Pore Water Pressure Variations. The variations of the pore water pressures of the 5 representing points (U1, U2, U3, U4, and U5) with time are presented in Figure 11. As addressed earlier, the annual precipitation is concentrated in three months while the remaining months of the year are with no precipitation. To be operatable, the rainfall of each month was concentrated in 2 hours with an incessant 


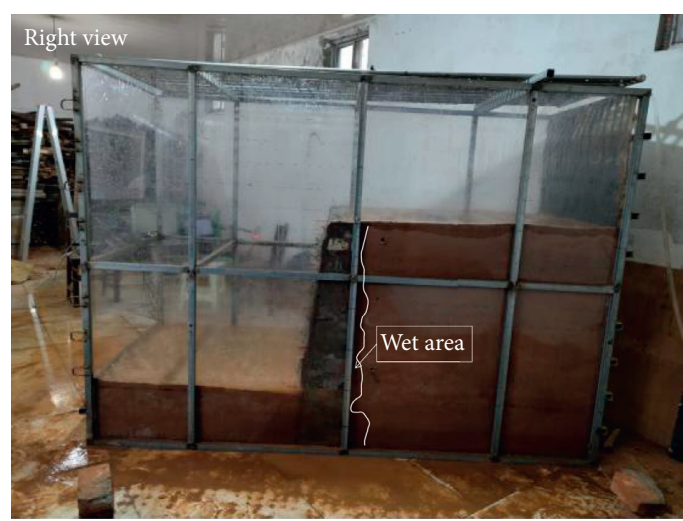

(a)

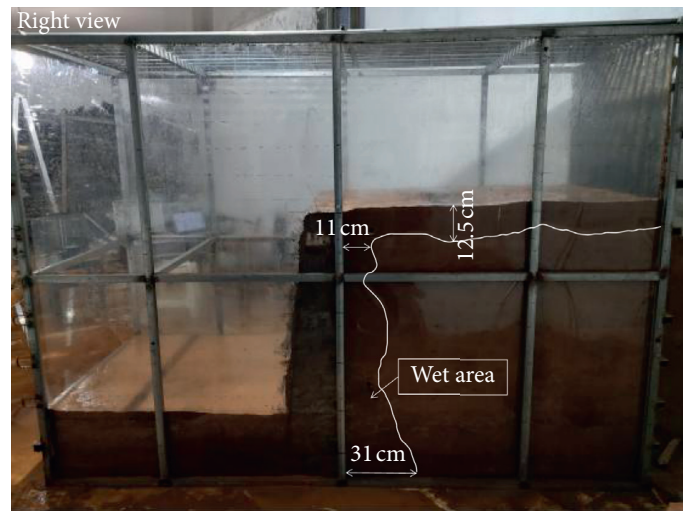

(c)

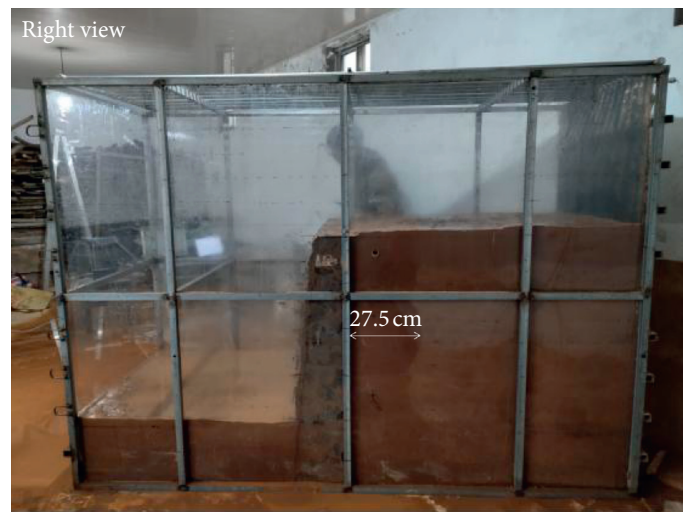

(e)

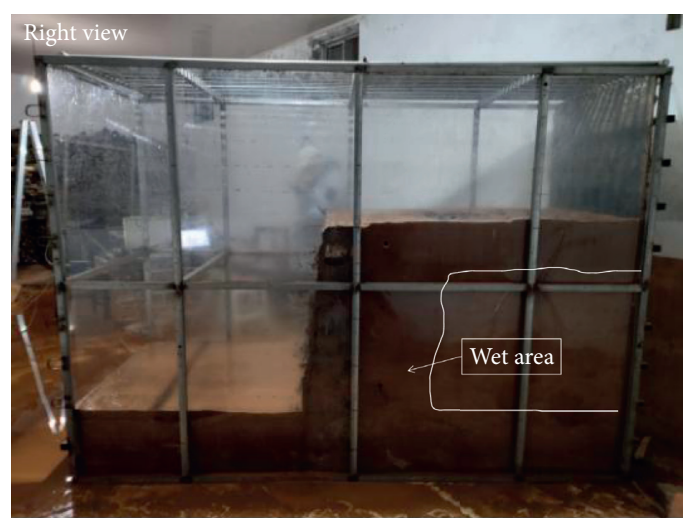

(g)

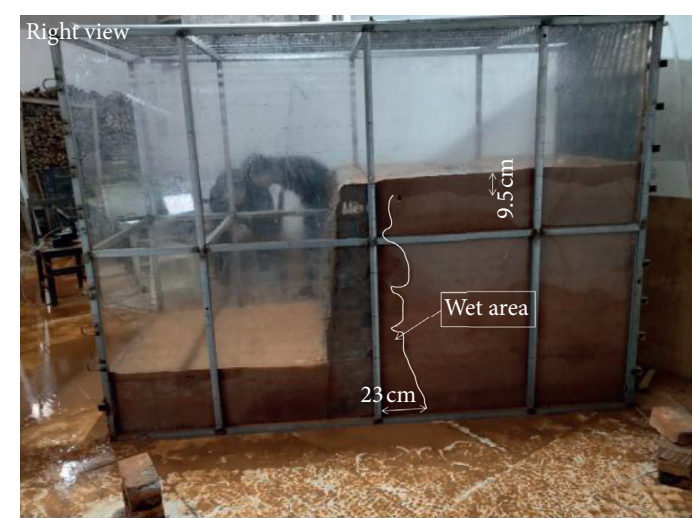

(b)

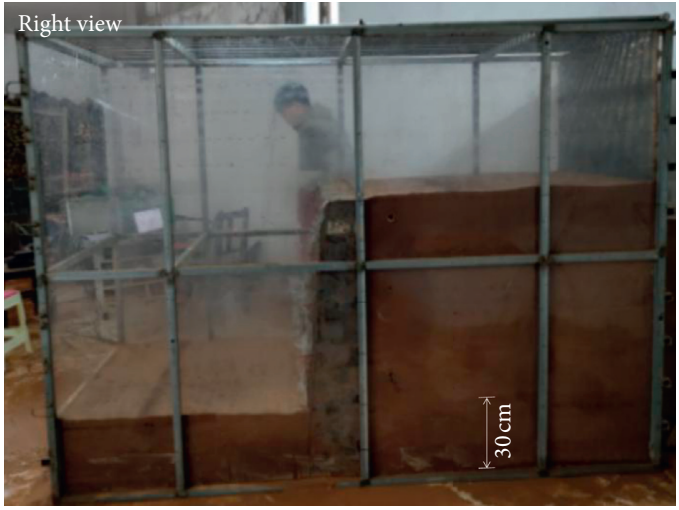

(d)

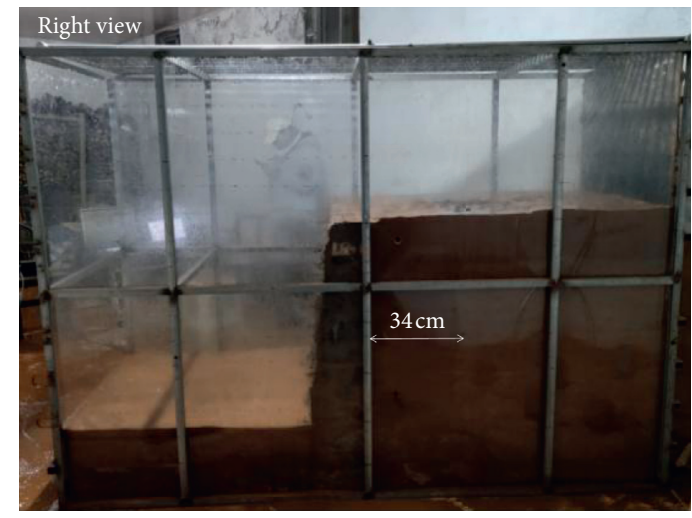

(f)

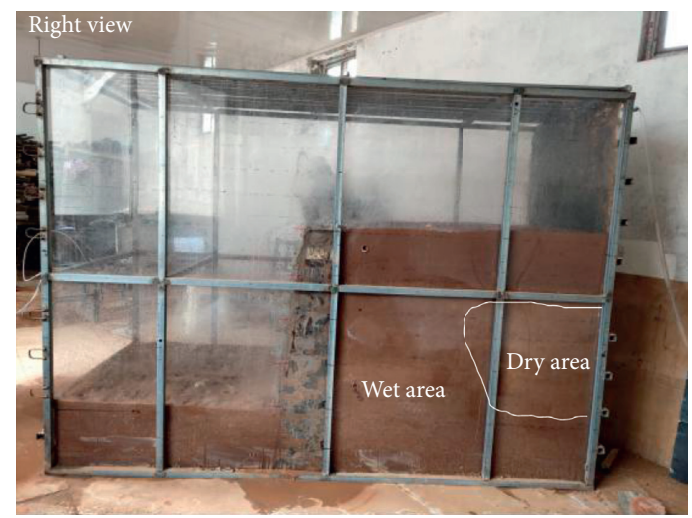

(h)

FIGURE 9: Rainwater infiltration behind the retaining wall within the first year. (a) First rainfall lasted for 20 minutes. (b) First rainfall lasted for 60 minutes. (c) First rainfall lasted for 120 minutes. (d) 5.2 hours after the first rainfall. (e) Second rainfall lasted for 120 minutes. (f) 5.2 hours after the second rainfall. (g) Third rainfall lasted for 120 minutes. (h) 70 hours after the third rainfall. 


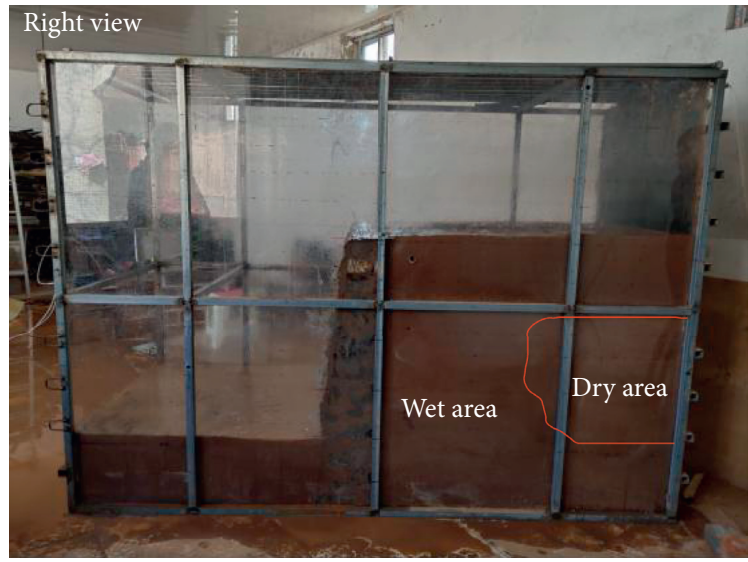

(a)

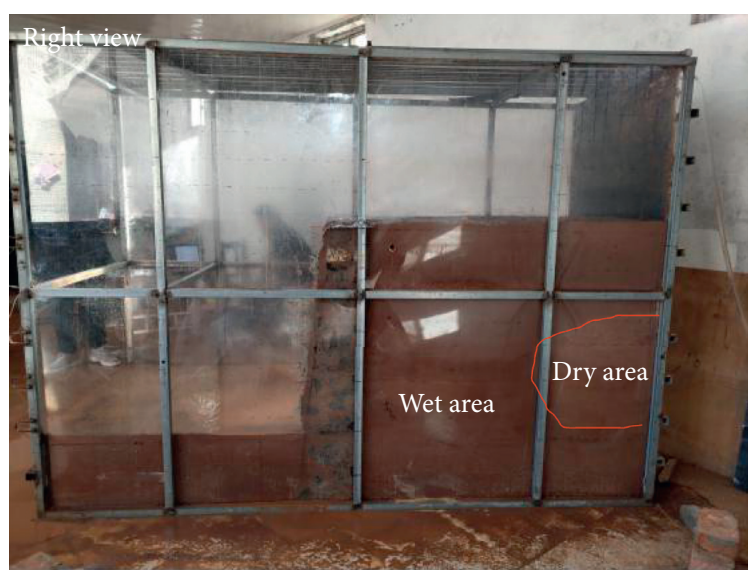

(c)

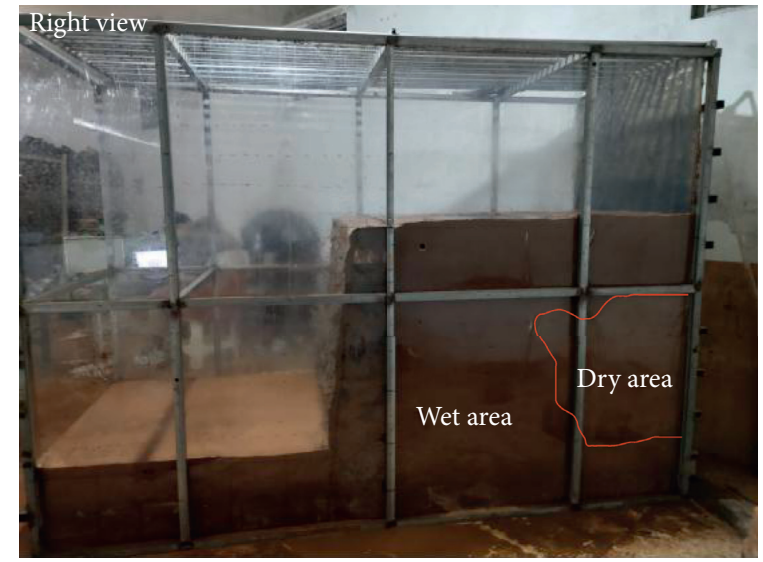

(b)

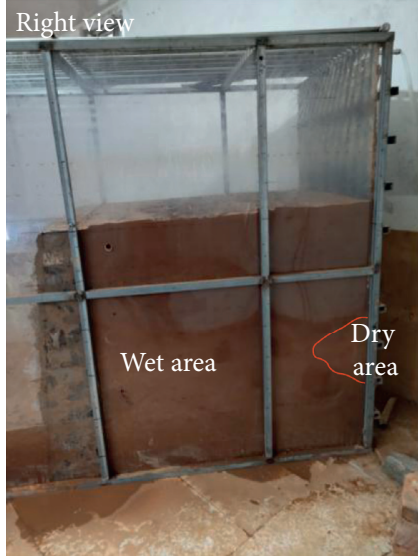

(d)

Figure 10: Rainwater infiltration behind the retaining wall within the second year. (a) First rainfall lasted for 120 minutes. (b) Second rainfall lasted for 120 minutes. (c) Third rainfall lasted for 120 minutes. (d) 70 hours after the third rainfall.

intensity. Evidently, during the 3 months of rainfall, the pore water pressure of the 5 points fluctuated acutely, with a general trend of increasing during raining and declining within the rainfall intervals. In the months without rainfall, the pore pressure of the 5 points was observed to be constant with negligible fluctuations. That is, the migration of water in the slope body led to little variation in the suction, which can be explained by the hysteresis phenomenon of the soil-water characteristic curve, by which the great change of water content induces little suction change in the dry condition. However, all the pore pressures presented in Figure 11 were negative and only the pore pressure of U5 increased from a negative value to about $0 \mathrm{kPa}$, which indicated the saturated status around point U5. As depicted in Figures 9 and 10, the rainwater preferentially accumulated at the heel of the retaining wall, which led to the saturation of the soil around point U5, inducing a pore pressure value of about $0 \mathrm{kPa}$ of U5. As delineated by Chueasamat et al. [50], the rainwater mainly concentrated at the slope toe, seeming consistent with this study at the heel of the retaining wall. Depending on Fredlund and Rahardjo [61] unsaturated soil theorem, the negative pore water pressures in the soil implies suctions, thereby indicating the unsaturated status of the soil. Thus, we can infer that the soils around all the five points except U5 were unsaturated in the 5 years of simulation. Therefore, we can come to a conclusion that although the wetting front passed the whole slope body, parts of the slope soils behind the retaining wall were retained at unsaturated status.

Additionally, we can find from Figures 7 and 9 that point U4 was close to the interface between the saturated and unsaturated areas, and thus, the pore water pressure of U4 was mostly influenced by the rainwater infiltration, increasing from about $-16 \mathrm{kPa}$ before the rainfall to about $-14 \mathrm{kPa}$ at the end of the fifth year. However, point U4 was situated above the saturated area, and the pore water pressure there could not increase to a positive value. Also, the pore water pressures of points $\mathrm{U} 2$ and $\mathrm{U} 3$ gave no obvious variation, especially $\mathrm{U} 3$, indicating the soils below the depth of $20 \mathrm{~cm}$ were not efficaciously affected by the rainfall. In most situations as simulated in the present study, the rainfall duration is limited, causing no deeper infiltration of rainwater, which is minified by the evaporation in the 
rainfall intervals. That was consistent with the practical project experience that the rainfall can merely influence the water content of the top 2 3 $\mathrm{m}$ thick layer of soil.

The pore water pressures with the depth at the end of the five years are presented in Figure 12. Because the permeability of the retaining wall varies irregularly, leading to the irregular variation of wetting extent of the soils along the wall back, the suction (negative pore water pressure) behind the wall showed no regular variation with depth, rather with a maximum suction value slightly above the saturation face. Accordingly, the most obvious variation of the suction with time was at the point sightly above the saturation face, which is due to the most drastic variation of water content near the saturation face in the rainfall process.

5.2. Soil Pressure Variations. The variations of the soil pressures of the 5 representing points (P1, P2, P3, P4, and P5) upon the wall back with time are presented in Figure 13. In the first year, the soil pressures of $\mathrm{P} 3$ and $\mathrm{P} 4$ increased considerably while the soil pressure of P1 fluctuated wildly around $-0.5 \mathrm{kPa}$, which can be deemed to be around $0 \mathrm{kPa}$ on account of measuring errors. Meanwhile, the soil pressures of P2 and P5 had no regular variation and however fluctuated around the zero value. This year, because the rainfall infiltration was not much, the soil pressures of $\mathrm{P} 1$, $\mathrm{P} 2$, and $\mathrm{P} 5$ varied hardly, meaning it had little influence by the rainfall infiltration. However, the variations of soil pressures of $\mathrm{P} 3$ and $\mathrm{P} 4$ could be attributed to the soil weight increments caused by the rainwater infiltration through the pore of the retaining wall. This was consistent with the pore water pressure variations delineated in Figure 12, which indicated the dominated effect of water penetrated through the wall pores at the wall toe (U4) and U3.

In the years later, the soil pressures of P2, P3, P4, and P5 had no obvious changes, which may be attributed to the limited change of the water content of the soils behind the retaining wall. As the rainwater penetrated through the wall, the soils behind the wall absorbed the water which continuously migrated backward, leading to the limited increase of the water content of the soil behind the wall and the expansion of the wet area behind the wall. However, the soil pressure of $\mathrm{P} 1$ sharply increased to about $4 \mathrm{kPa}$ after the third year of rainfall, which was lifted to about $11 \mathrm{kPa}$ at the end of the fourth year. At the end of the fifth year, the soil pressure of $\mathrm{P} 1$ declined to approximately $6 \mathrm{kPa}$. Reasonably, the variation of the soil pressure of $\mathrm{P} 1$ could be attributed to the softening of the superficial soil caused by the direct infiltration of the rainwater into the crest of the slope. With the progress of the rainfall, the top layer of the slope was softened, leading the soils there to flow toward the wall back like fluid, thus causing the sharp increase of soil pressure of P1. As the wall inclined outward, the soil pressure of P1 decreased considerably in the fifth year, for the pressure releasing effect caused.

Figure 14 delineates the distribution of the soil pressures upon the wall back with depth at the end of the five years. It can be seen that, before the end of the third year, the soil pressures increased with depth above $80 \mathrm{~cm}$, while the maximum value was about $1.35 \mathrm{kPa}$ at the depth of $80 \mathrm{~cm}$. As the soil pressures upon the wall back are caused by the soil weight pressures increasing with depth, the soil pressures upon the wall back increased with depth correctly. However, the soil pressure decreased with depth in the slope base (within the depth of $86 \mathrm{~cm}$ to $116 \mathrm{~cm}$ ), while the value at the depth of $100 \mathrm{~cm}$ was about $0.1 \mathrm{kPa}$, which could be attributed to the soil arch effect in the deep layer. In the third and following years, for the softening effect of the rainwater, the soil pressure at the depth of $20 \mathrm{~cm}$ increased sharply which was approximately $11 \mathrm{kPa}$ at the end of the fourth year, while the soil pressures of other positions showed no obvious variation with time. Despite the sharp increment of the pressure at the depth of $20 \mathrm{~cm}$, the variation law of soil pressures upon the wall back with depth was consistent with the findings of Liu et al. [62], which suggested the maximum soil pressures at the position of $z / H$ (ratio of burying depth to the height of the retaining wall) between 0.6 and 0.9 . These findings are going to be valuable in determining the wall back soil pressures while the postevaluation of the prototype project in the later section.

\section{Displacements of the Retaining Wall}

The distances between the 5 key points and a fixed point were measured by the laser rangefinder (as shown in Figure 7), the differences of which before and after rainfall were defined as the horizontal displacements for the corresponding points. Figure 15 shows the horizontal displacement variations of the 5 key points with time. In the first year, a general varying pattern of the horizontal displacements with time for the five points was that the displacements increased obviously during rainfall, however with no regular variation after rainfall. With the progress of the rainfall, the soils of the slope were wetted, which lessened the internal frictional angle and the cohesion of the slope soil, thus leading to the larger soil pressures upon the wall back and the less resistance of the slope base, which ultimately caused the deformation of retaining wall. At the end of the first year, the slope shoulder (S1) had the largest displacement of approximately $10 \mathrm{~mm}$, and the point near the slope toe (S5) had the minimum displacement of nearly $1.0 \mathrm{~mm}$, implying the inclination of the retaining wall. That is, the soil pressures upon the wall back and the soil resistance in front of the wall formed a couple, which contrarotated the wall showing a displacement forward in the upper part of the wall. However, the displacements of S3 and S4 were larger than that of S2, suggesting the extrusion of the wall around S3 and S4, which was consistent with the field survey results (see Figure 2). That could probably be attributed to the soil pressure distributions upon the wall back which increased to a relatively higher value near the elevation of S3 and S4 where the relatively lower wall thickness could not resist. Summarily, the retaining wall had a deformation consisting of an inclining forward and an extrusion in the middle height of the wall.

In the second year, the displacement variation pattern was similar to the first year, while the increment of the displacements in the rainfall duration was more moderate than the first year. At the end of the second year, the horizontal displacement of $\mathrm{S} 1$ was about $11 \mathrm{~mm}$, while the 

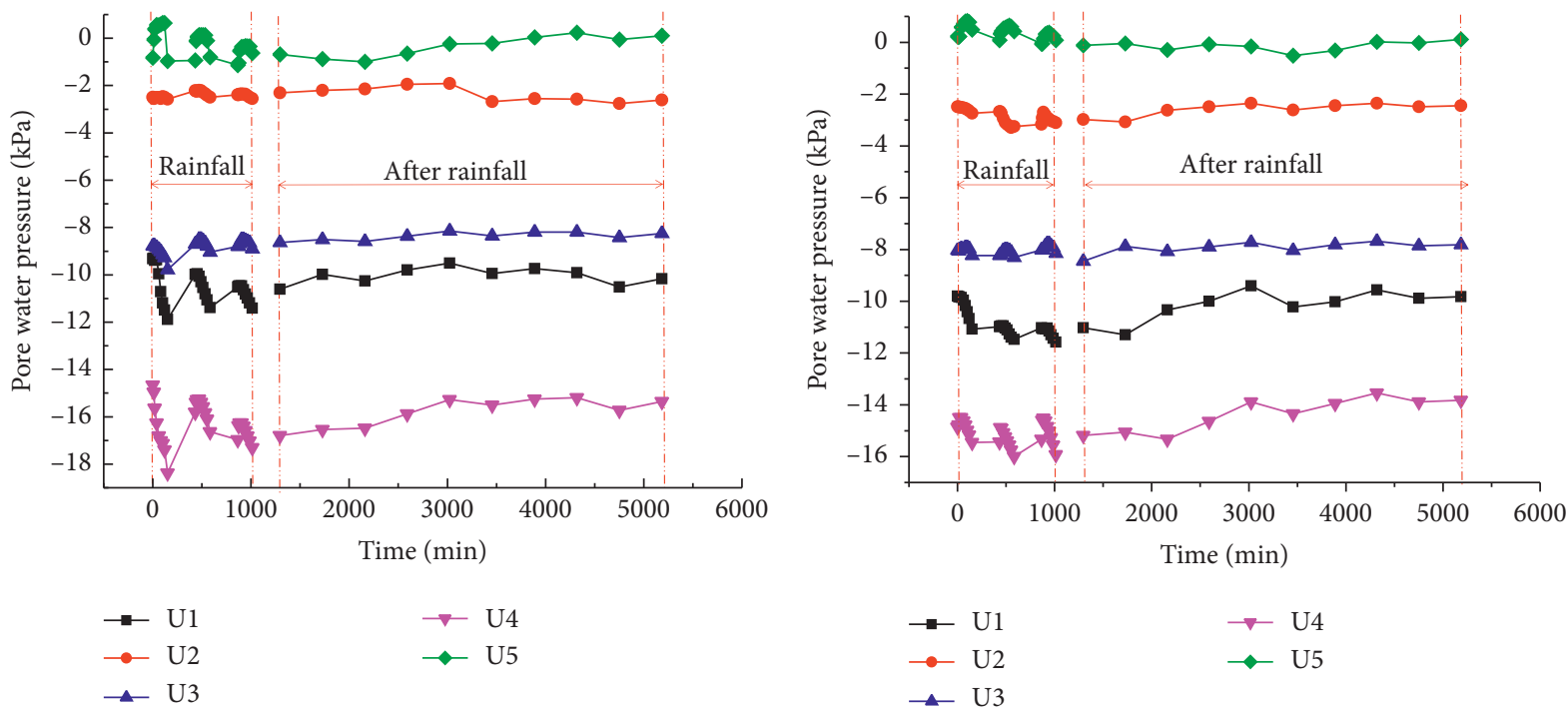

(a)

(b)
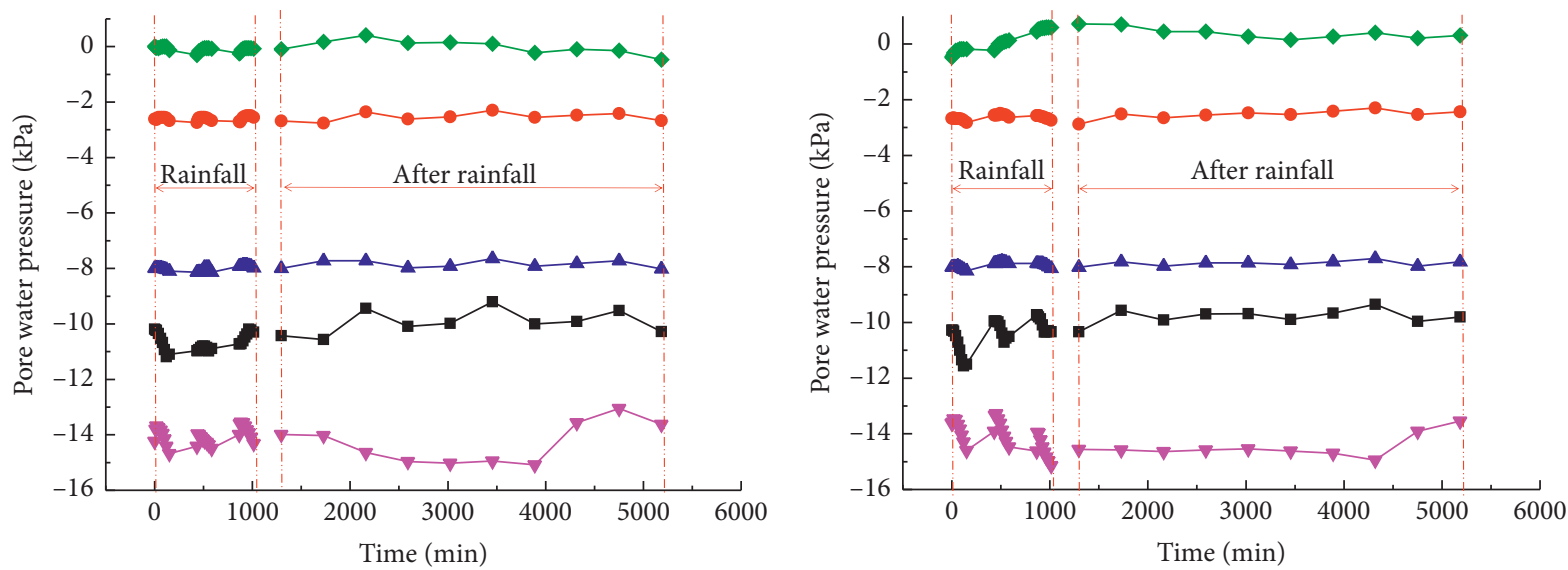

$\rightarrow \mathrm{U} 1$
$\rightarrow \mathrm{U} 2$
$\simeq \mathrm{U} 3$

$\rightarrow \mathrm{U} 4$

$\rightarrow \mathrm{U} 1$

$\rightarrow \quad$ U4

$\rightarrow$ U2

$\multimap$ U5

(c)

(d)

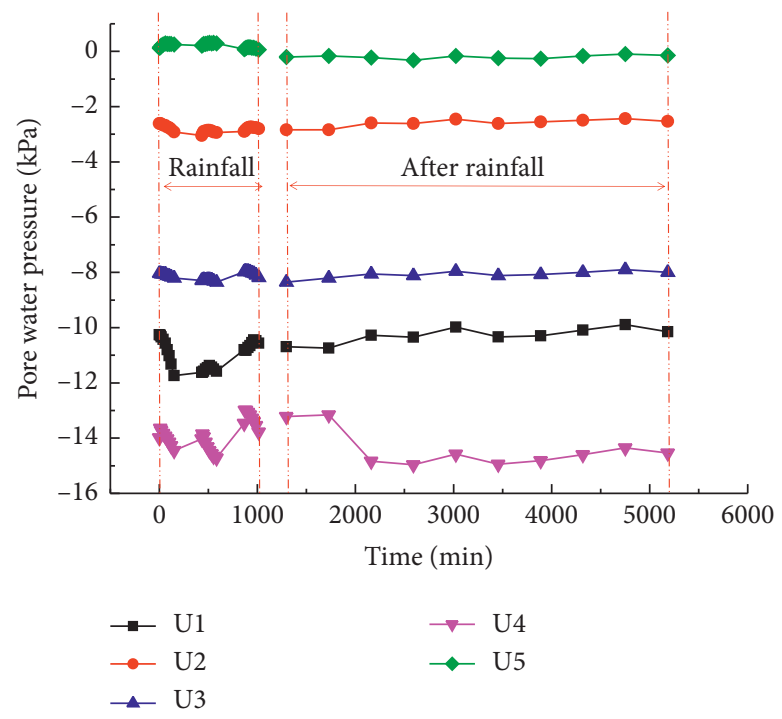

(e)

Figure 11: Pore water pressure variations within the test. (a) First year. (b) Second year. (c) Third year. (d) Fourth year. (e) Fifth year. 


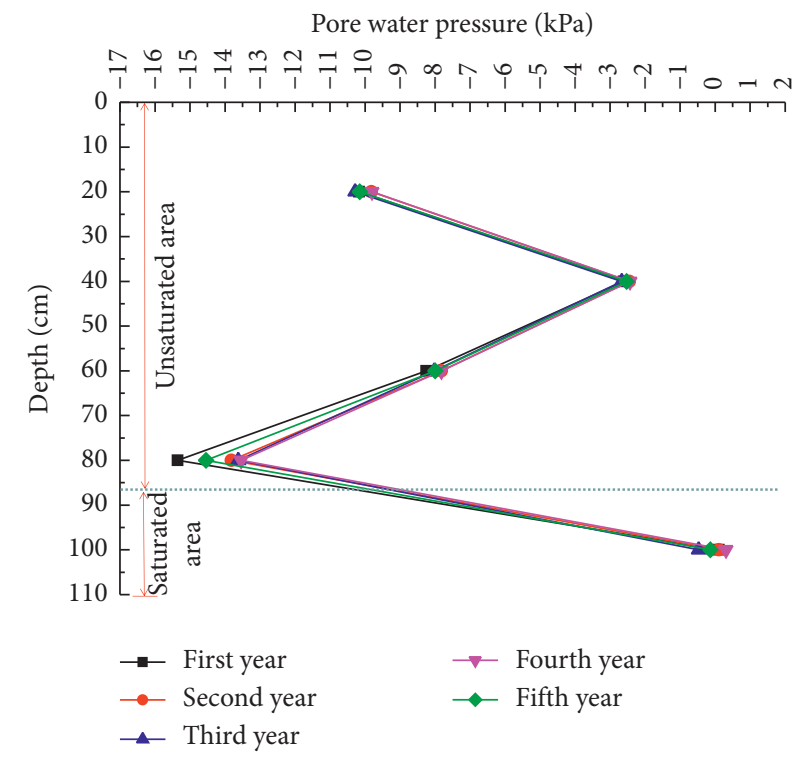

Figure 12: Pore water pressure variations with depth at the end of the five years.
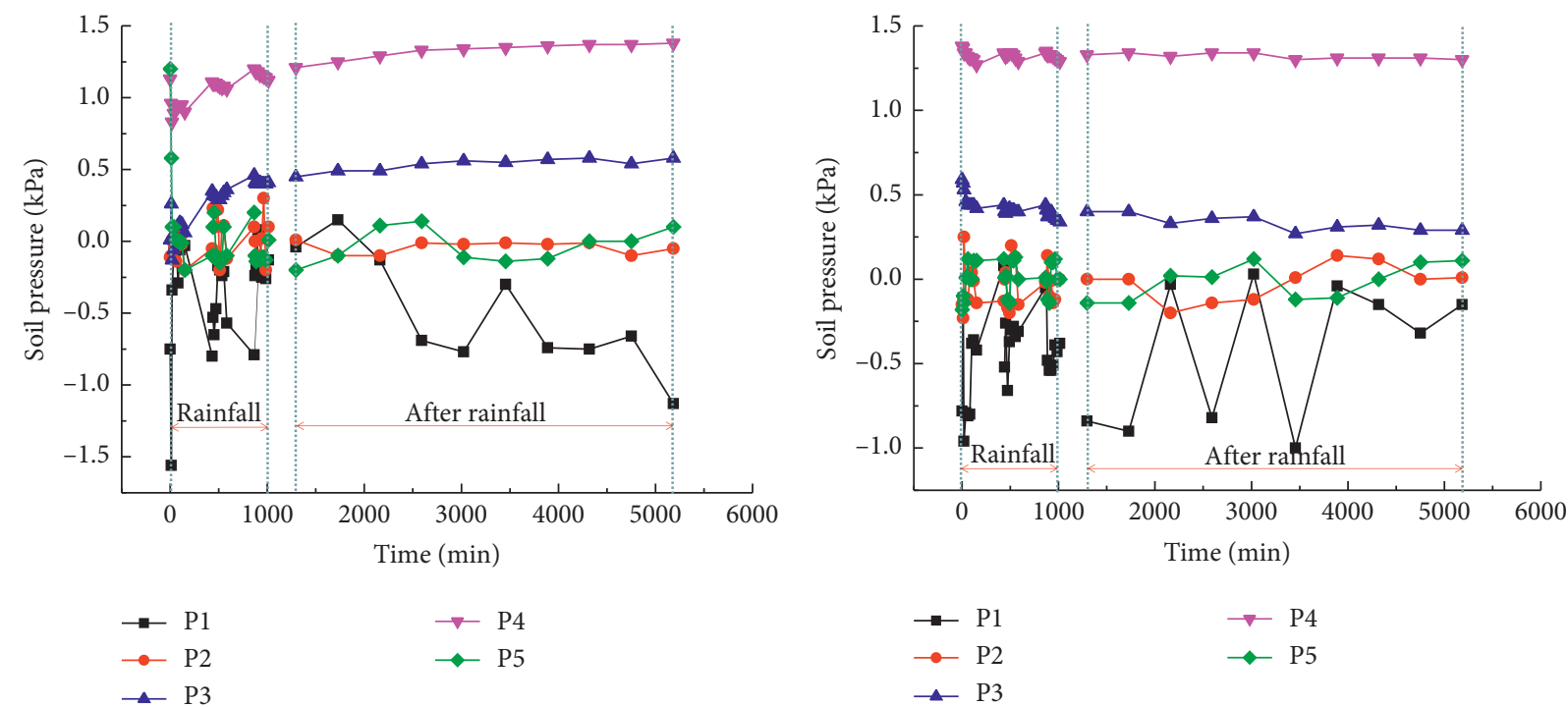

- P1

$\rightarrow \mathrm{P} 4$

$\rightarrow \mathrm{P} 2$

(b)

(a)

Figure 13: Continued. 


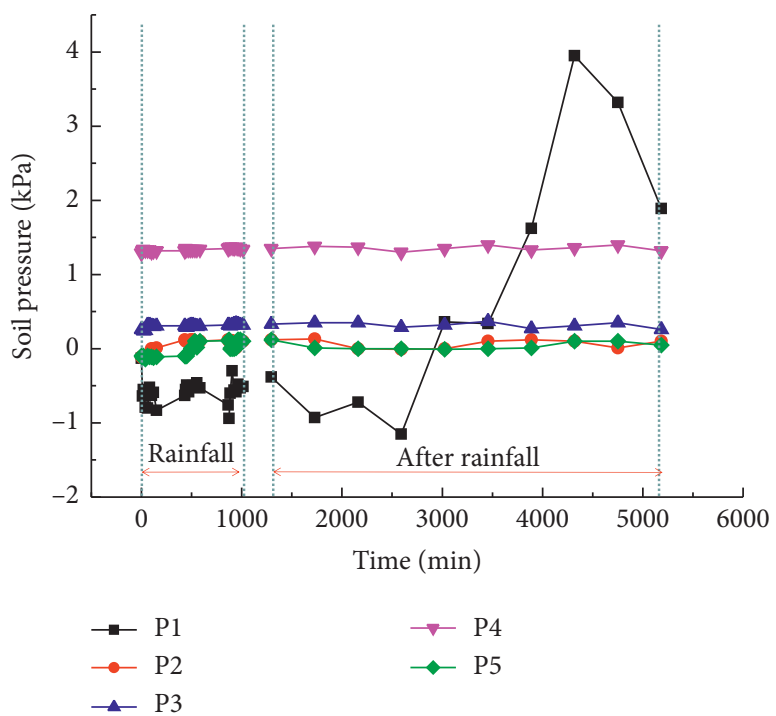

(c)

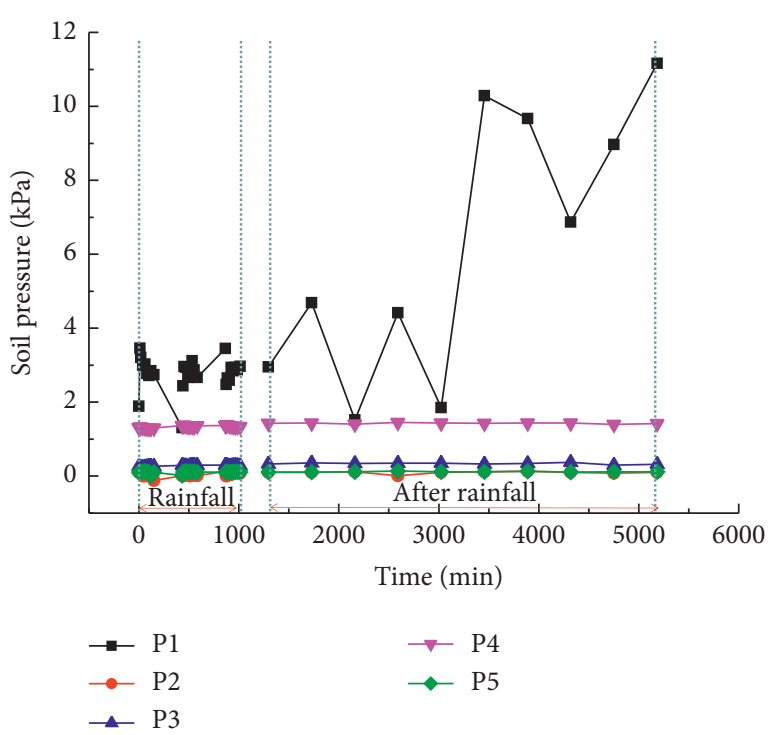

(d)

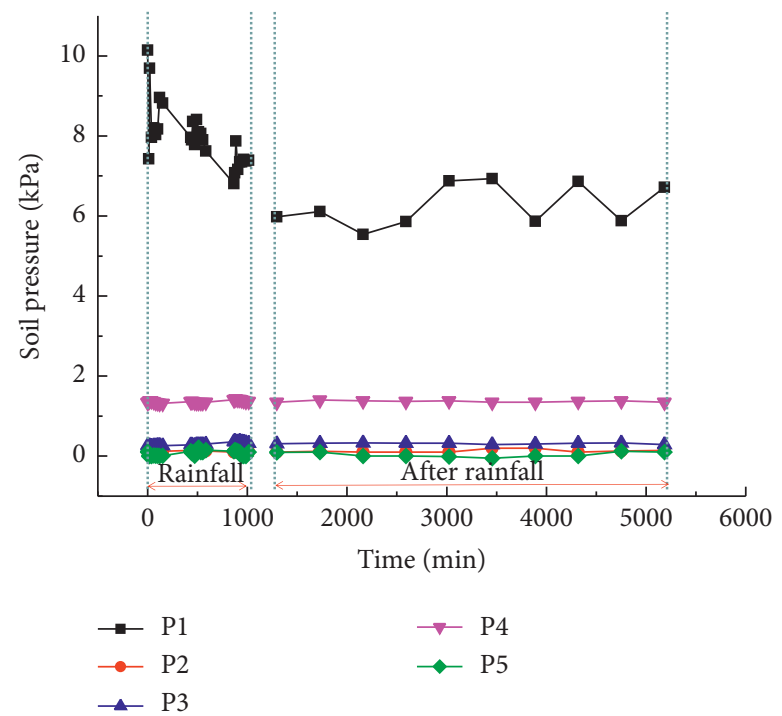

(e)

FIGURE 13: Variations of soil pressure upon the retaining wall back. (a) First year. (b) Second year. (c) Third year. (d) Fourth year. (e) Fifth year.

horizontal displacement of S5 increased to about $3.0 \mathrm{~mm}$. That is, in the second year of rainfall, more rainwater accumulated in the front of the wall, softening the soils there, thus lessening the soil resistance there, which caused the considerable deformation near the slope toe (S5). In the following years, the displacements of the retaining wall had no detectable change, despite the slight increment of $1.0 \mathrm{~mm}$ in the third year for S1, which suggested that the retaining wall entered a relatively stationary status after the third year.

Figure 16 delineates the variations of the horizontal displacements of the five points with the vertical distance from the slope shoulder at the end of the five years. Here, it is clear that the displacements decreased with the vertical distance from the slope shoulder, despite the convex at S3 and S4. It is of substantial interest that the extrusion position of the prototype was at the middle of the retaining wall face, which was just corresponding to the position of S3. Thus, it is reasonable to say the larger soil pressure near S3 is responsible for the corresponding wall extrusion. These findings just validated the soundness of the model test in this study and could be used in the next section of postevaluation of the project.

\section{Postevaluation of the Treating Project}

Postevaluation was instigated into slope treating project in China by Zheng [10], who proposed the concept of postevaluation of slope treating project which differs from preevaluation. In pre-evaluation, technicists concern about the safety of the project just after the completion of construction. However, in postevaluation, they often concern about 


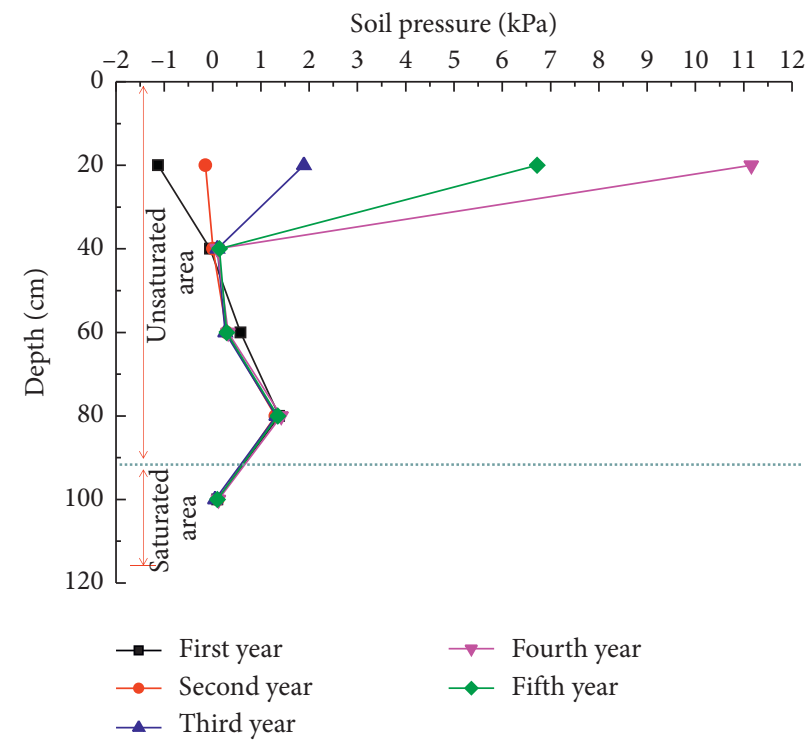

FIGURE 14: Variations of soil pressure upon the retaining wall back with depth at the end of the five years.
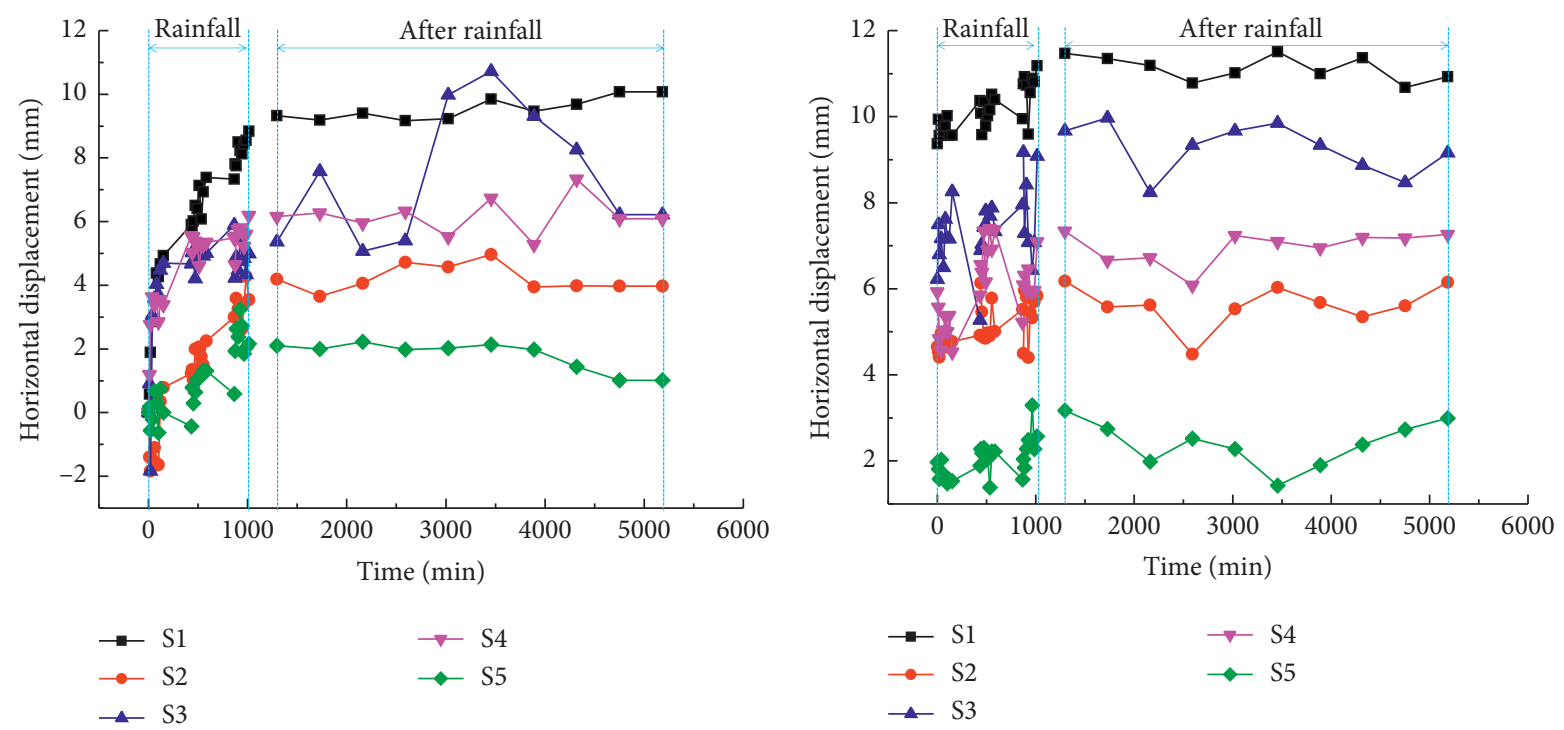

$$
\rightarrow \mathrm{S} 4
$$$$
\rightarrow \mathrm{S} 1
$$$$
\rightarrow \mathrm{S} 4
$$$$
\rightarrow \mathrm{S} 2
$$$$
\multimap \text { S5 }
$$

(a)

(b)

Figure 15: Continued. 

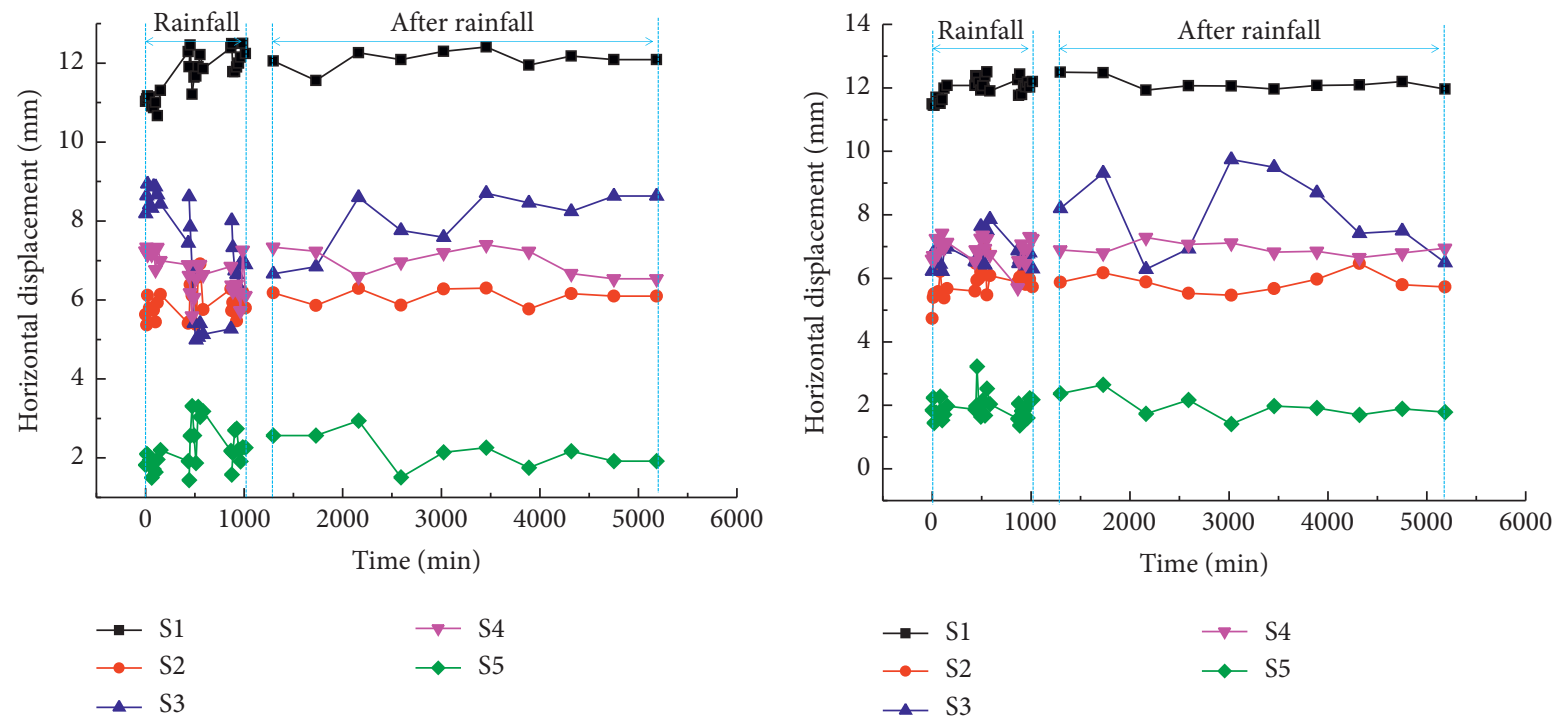

(c)

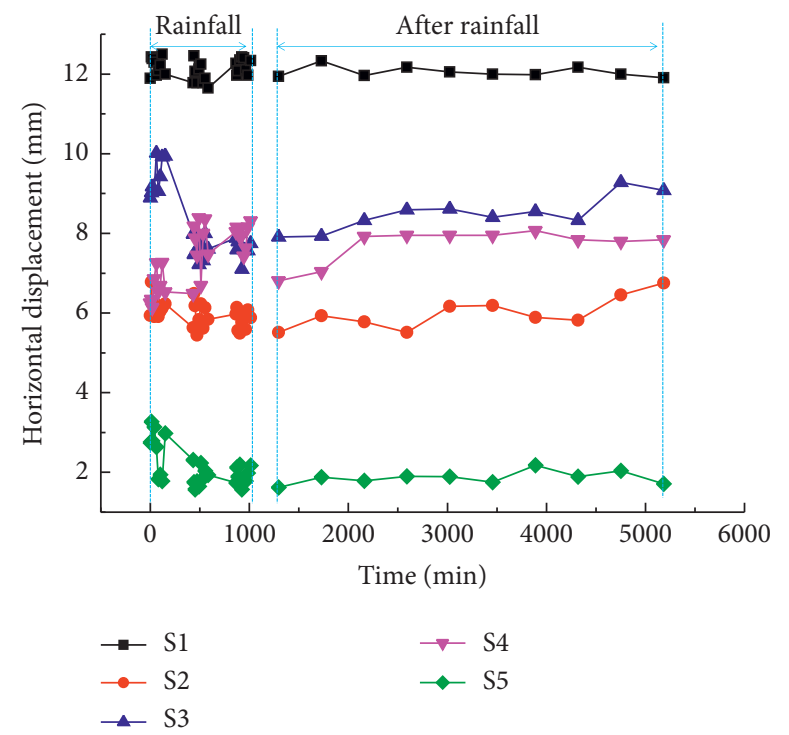

(e)

Figure 15: Variations of horizontal displacements of the five key points with time. (a) First year. (b) Second year. (c) Third year. (d) Fourth year. (e) Fifth year.

the safety after a considerable long term of operation and the running status of it. As Zheng addressed, the displacement rate of retaining structure top not greater than $0.1 \mathrm{~mm}$ /day could be put to use as an indicator of the structure safety. In addition, the ratio of measured force and the designed force $\left(R_{t}\right)$ upon the retaining structure was adopted as the indicator of the treating effect of the project, which is detailed in Table 4. On the basis of the deforming and failure degree of the structure, some qualitative criteria (see literature 10) were also proposed judging the treating effect of the project. In accordance with the above criteria, this section uses the field investigation data and the model test data to postevaluate the treating effect of the prototype project.
7.1. Postevaluation Based on the Deformation and Failure Degree. According to Figure 16, at the end of the fifth year, the horizontal displacement of the retaining wall top was about $12 \mathrm{~mm}$, from which the horizontal displacement of the prototype wall top was $120 \mathrm{~mm}$. Also, the extruding height at point S3 was about $4.0 \mathrm{~mm}$ at the end of the fifth year, from which the extruding height of the prototype wall was about $40.0 \mathrm{~mm}$. Thus, the ratio of the wall top displacement to the wall height was approximately 0.01 , while the ratio of the extruding height to the wall height was approximately 0.003 . Consequently, the maximum displacement ratio could be deemed as $1.0 \%$, just being a local displacement which did not have much influence on the operation of the wall. 


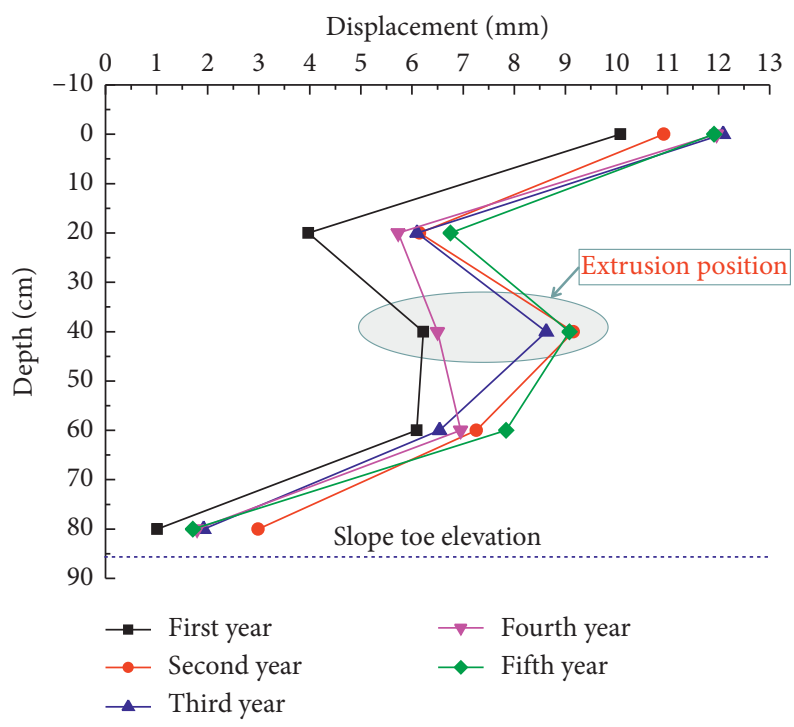

Figure 16: Variations of horizontal displacements with depth at the end of the five years.

TABLE 4: Ratio of the measured force and the designed force $\left(R_{t}\right)$ with treating effect.

\begin{tabular}{lc}
\hline Indicator value range & Treating effect \\
\hline $0.6 \sim 1.0$ & Very good \\
$0.4 \sim 0.6$ & Good \\
$0.15 \sim 0.40$ & Not bad \\
$<0.15$ or $>1.0$ & Conservative or failed \\
\hline
\end{tabular}

Thence, the treating effect of the project could possibly be preliminarily judged as very good or good according to Zheng's qualitative criteria.

7.2. Postevaluation Based on the Displacement Rate. According to Figure 15, the displacement of the retaining wall top was about $0.11 \mathrm{~mm}$ during the fifth year, from which the prototype wall top displacement was $1.1 \mathrm{~mm}$ in the fifth year. Thus, the ultimate displacement rate of the prototype wall top in the fifth year was approximately $3.05 \times 10^{-3} \mathrm{~mm} /$ day, conveying the safety of the treating project. As a result, the treating effect of the project could be again judged as very good or good according to the qualitative criteria of Zheng.

7.3. Postevaluation Based on $R_{t}$. Figure 14 presents the soil pressure distribution upon the retaining wall back at the end of the fifth year, from which we derived the resultant soil force upon the prototype wall back as shown in Figure 17. From Figure 12, the pore water pressure upon the wall back was less than or equal to $0 \mathrm{kPa}$, which did not exert any influence on the wall stability, and thus was neglected. Adding up the shaded area in Figure 17, the resultant soil force upon the wall back $F_{t}$ was derived as $172.6 \mathrm{kN}$.

According to the theorem of active soil pressure upon wall back for unsaturated soils proposed by Sahoo and Ganesh [63], the active soil pressure upon the wall back can be delineated as

$$
E_{a}=\frac{1}{2} \gamma H^{2} K_{a}
$$

Here, $K_{a}$ is the active soil pressure coefficient considering the matrix suction, the value of which is between 0.3 and 0.35 under the condition of rainfall according to the literature [63]. $\gamma$ is the unit weight of the soil, $c$ is the cohesion of the soil, $\varphi$ is the internal friction angle of the soil, and $H$ is the wall height. According to Table 1 , the parameter $\rho=1.42 \mathrm{~g} /$ $\mathrm{cm} 3, \varphi=27^{\circ}$, and $c=15.0 \mathrm{kPa}$. Thus, $\gamma=\rho \mathrm{g}=14.2 \mathrm{kN} / \mathrm{m} 3$, $K_{a}=0.3 \sim 0.35$. Substituted these parameter values into Equation (7), we derived $E_{a}=286.61 \sim 334.38 \mathrm{kN}$.

$$
R_{t}=\frac{F_{t}}{E_{a}}=\frac{172.6}{286.61 \sim 334.38}=0.52 \sim 0.60 .
$$

According to Table 4, the treating effect of the prototype project in this preliminary evaluation section should be good.

7.4. Evaluating Results and Postevaluation Frame. Conservatively, to guarantee the correctness of the evaluation process, synthesizing the above evaluating results, the treating effect of the project should be good.

Lastly, it is noteworthy that the postevaluation frame formed in this paper is essential to be adopted in other slope treating projects that employed retaining walls. Thus, this evaluation frame is delineated in Figure 18. 


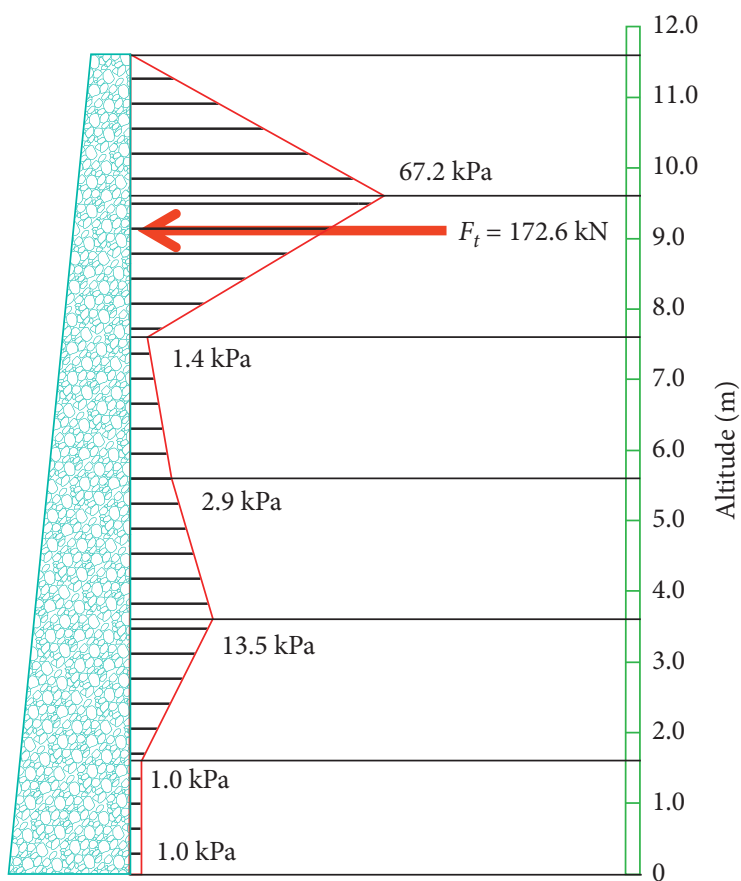

FIGURE 17: The resultant soil force upon the prototype retaining wall back.

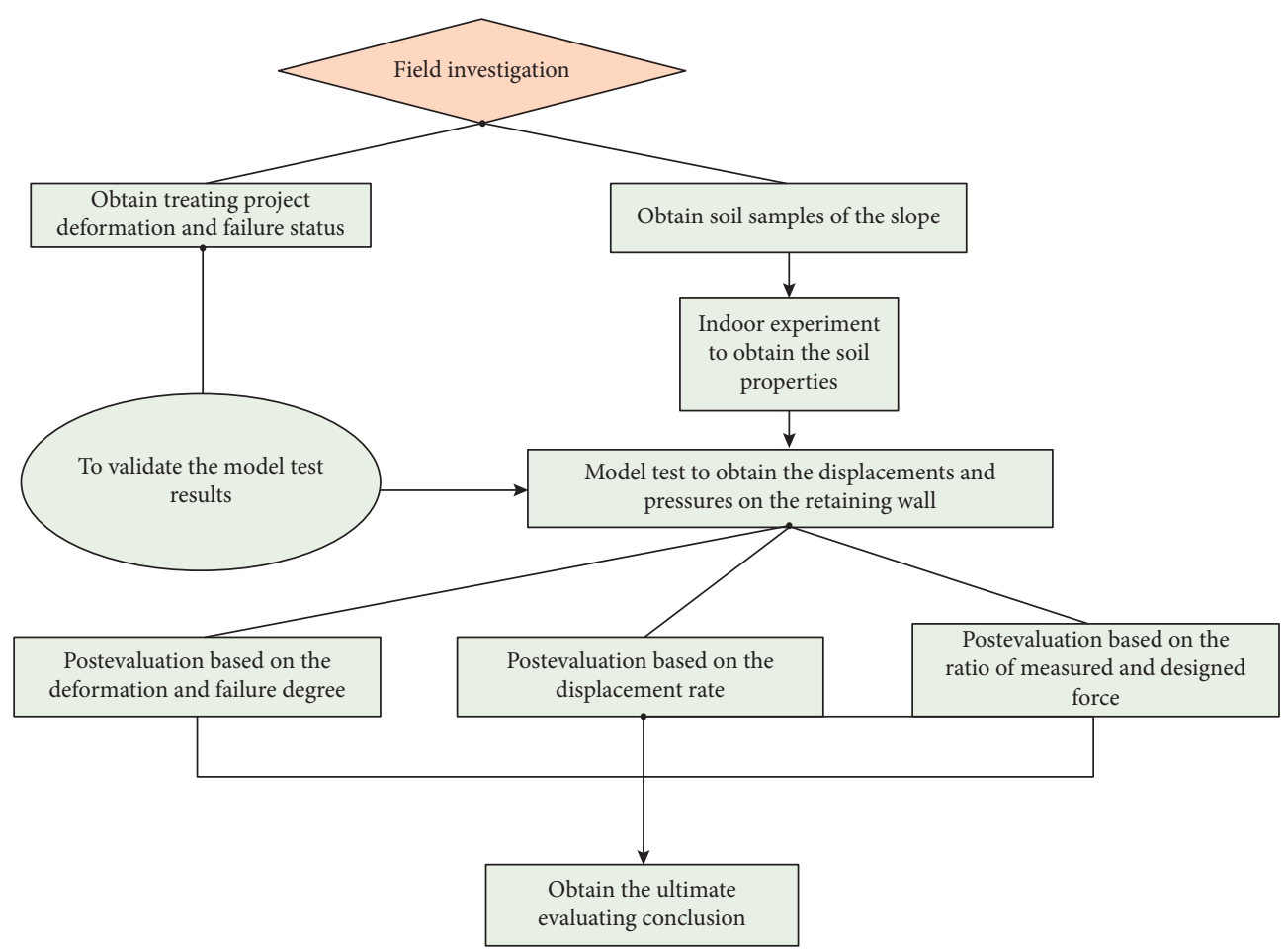

FIgURe 18: Postevaluation frame for retaining wall treating slopes.

\section{Conclusion}

To divulge the influence of long-term rainfall on the loess slope situated in Yan'an City of Shaanxi Province treated by retaining wall, field investigations, and indoor model tests were performed, the results of which were adopted to conduct the postevaluation of the retaining wall treating project of the slope. The following conclusions were therefore obtained:

(1) The rainwater preferentially penetrates along the interface between the front soil and the retaining wall 
and accumulates at the slope toe. The accumulated rainwater then migrates forward horizontally and gradually submerses the whole front soil, softening the front soil which is adverse to the stability of the retaining wall. Thus, effective measures should be taken to prevent the rainwater from penetrating along the interface between the front soil and the retaining wall, alleviating the failure disaster to the retaining wall.

(2) Behind the retaining wall, the rainwater penetrates preferentially along the wall back, associating with the penetration of rainwater through the wall body. The penetrating rainwater accumulates mostly at the heel of the retaining wall, forming the larger width of wet area at the bottom of the slope, consequently softening the soil there, which is unfavorable to the safety of the retaining wall. Thus, effective measures should be taken to prevent rainwater from penetrating along the wall back and through the wall body.

(3) Even though the whole slope body is submersed during the rainfall process, the pore water pressures behind the retaining wall retain negative or zero, implying that the soil here is unsaturated.

(4) In the first year, the soil pressure upon the wall back at the intermediate height of the slope had a weakly visible increase, while the other positions hardly have variation. In the third year and thereafter, the soil pressure upon the wall back at the upper layer increases wildly, while the other positions remain unchanged. Regardless of the peculiarly large soil pressure upon the wall back at the top layer, the soil pressure increases to a considerable value and then drops with the depth along the wall back.

(5) In the first two years, the horizontal displacements of the retaining wall increased visibly and then retained with no regular variation with time. For this special project, at the end of the five years, the retaining wall has an obvious extrusion at the intermediate height of the slope, which is consistent with the investigation results.

(6) The above results were adopted to perform the postevaluation of the retaining wall treating project of the slope, which structured the frame for the postevaluation of retaining wall treating loess slope under long-term rainfall (see Figure 18). This evaluation frame can be valuable to other slope treating projects.

\section{Data Availability}

The data used to support the findings of this study are available from the corresponding author upon request.

\section{Conflicts of Interest}

The authors declare that they have no conflicts of interest.

\section{Acknowledgments}

This research was financially supported by the Key R \& D Program of Shaanxi Province (2018GY-099) and the Key R \& D Program of Shangluo City (2020-Z-0111). The authors are very grateful to professor Wanjun Ye from for his help.

\section{References}

[1] G. A. Tang, F. Y. Li, and X. J. Liu, "Research on the slope spectrum of the Loess Plateau," Science in China Series E: Technological Sciences, vol. 51, no. 1, pp. 175-185, 2008.

[2] S. Hu, H. J. Qiu, and N. L. Wang, "The influence of loess cave development upon landslides and geomorphologic evolution: a case study from the northwest Loess-Plateau, China," Geomorphology, vol. 359, p. 16, Article ID 107167, 2020.

[3] M. Zhang and J. Liu, "Controlling factors of loess landslides in western China," Environmental Earth Sciences, vol. 59, no. 8, pp. 1671-1680, 2010.

[4] W.-Z. Guo, L. Luo, W.-L. Wang et al., "Sensitivity of rainstorm-triggered shallow mass movements on gully slopes to topographical factors on the Chinese Loess Plateau," Geomorphology, vol. 337, pp. 69-78, 2019.

[5] Y. M. Tang, Q. Xue, Z. G. Li, and W. Feng, "Three modes of rainfall infiltration inducing loess landslide," Natural Hazards, vol. 79, no. 1, pp. 137-150, 2015.

[6] J. Peng, S. Wang, Q. Wang et al., "Distribution and genetic types of loess landslides in China," Journal of Asian Earth Sciences, vol. 170, pp. 329-350, 2019.

[7] T. Guo, Q. Wang, D. Li, and J. Zhuang, "Effect of surface stone cover on sediment and solute transport on the slope of fallow land in the semi-arid loess region of northwestern China," Journal of Soils and Sediments, vol. 10, no. 6, pp. 1200-1208, 2010.

[8] Z. Mao, N. An, R. Li, L. Xu, and H. Wu, "Treatment effect analysis on shallow buried bias slope section of tunnel based on fuzzy comprehensive evaluation," Geotechnical and Geological Engineering, vol. 38, no. 5, pp. 4463-4477, 2020.

[9] Z. M. Zhao, Research on Stability Evaluation Criterion and Method for Engineering Treatment Rock Slope-Based on YuanMo Expressway, Doctor Degree Dissertation, Southwest Jiaotong University, Chengdou, China, 2004, in Chinese.

[10] M. X. Zheng, Study on the Post Evaluation of the Effectiveness of Landslide Control, Doctor Degree Dissertation, Hohai University, Nanjing, China, 2005, in Chinese.

[11] E. M. Liang, Analysis of K98 Landslide in Beijing-ZhuhaiNorth and Evaluation of Treatment Engineering Effect Master Degree Dissertation, Kunming University of Science \& Technology, Kunming, China, 2010, in Chinese.

[12] S. J. Liu, Research on Slope Security Assessment Method of Mountain Expressway, Master Degree Dissertation, Chongqing Jiaotong University, Chongqing, China, 2012, in Chinese.

[13] H. H. Tian, Evaluation of Treatment Effect of Highway Landslide, Master Degree Dissertation, Central South University, Changsha, China, 2009, in Chinese.

[14] J. Chen, L. Wang, and X. Pu, "Experimental study on the dynamic characteristics of low angle loess slope under the influence of long-and short-term effects of rainfall before earthquake," Engineering Geology, vol. 273, Article ID 105684, 2020.

[15] I. Egeli and H. F. Pulat, "Mechanism and modelling of shallow soil slope stability during high intensity and short duration rainfall," Scientia Iranica, vol. 18, no. 6, pp. 1179-1187, 2011. 
[16] K. Sasahara and N. Sakai, "Shear and compression strain development in sandy model slope under repeated rainfall," Soils and Foundations, vol. 57, no. 6, pp. 920-934, 2017.

[17] M. S. Kim, Y. Onda, T. Uchida, J. K. Kim, and Y. S. Song, "Effect of seepage on shallow landslides in consideration of changes in topography: case study including an experimental sandy slope with artificial rainfall," Catena, vol. 161, pp. 5062, 2018.

[18] H. Rahardjo, T. T. Lee, E. C. Leong, and R. B. Rezaur, "Response of a residual soil slope to rainfall," Canadian Geotechnical Journal, vol. 42, no. 2, pp. 340-351, 2005.

[19] J. J. Gan and Y. X. Zhang, "Analysis of model tests of rainfallinduced soil deposit landslide," Advances in Civil Engineering, vol. 2020, p. 13, Article ID 6431247, 2020.

[20] T. Hai, K. Ling-wei, and L. I. Bo, "Centrifugal modeling tests on stability of deposits slope under rainfall," Rock and Soil Mechanics, vol. 36, no. 11, pp. 3180-3186, 2015.

[21] G. Cai, M. Li, and B. Han, "Numerical analysis of unsaturated soil slopes under rainfall infiltration based on the modified glasgow coupled model," Advances in Civil Engineering, vol. 2020, p. 13, Article ID 8865179, 2020.

[22] M. S. Masoudian, M. A. H. Afrapoli, and A. Tasalloti, “A general framework for coupled hydro-mechanical modelling of rainfall-induced instability in unsaturated slopes with multivariate random fields," Computers and Geotechnics, vol. 115, Article ID 103162, 2019.

[23] H. Wang and J. Li, "Analytical solutions to the one-dimensional coupled seepage and deformation of unsaturated soils with arbitrary nonhomogeneous boundary conditions," Transport in Porous Media, vol. 108, no. 2, pp. 481-496, 2015.

[24] D. J. Wang, H. M. Tang, and Y. H. Zhang, "An improved approach for evaluating the time-dependent stability of colluvial landslides during intense rainfall," Environmental Earth Sciences, vol. 76, no. 8, p. 321, 2017.

[25] M. Yuan, Y. Zhang, and Y. Zhao, "Effect of rainfall gradient and vegetation restoration on gully initiation under a largescale extreme rainfall event on the hilly Loess Plateau: a case study from the Wuding River basin, China," Science of the Total Environment, vol. 739, p. 11, Article ID 140066, 2020.

[26] M. Bordoni, C. Meisina, R. Valentino, N. Lu, M. Bittelli, and S. Chersich, "Hydrological factors affecting rainfall-induced shallow landslides: from the field monitoring to a simplified slope stability analysis," Engineering Geology, vol. 193, pp. 19-37, 2015.

[27] Z. Yang, H. Cai, W. Shao et al., "Clarifying the hydrological mechanisms and thresholds for rainfall-induced landslide: in situ monitoring of big data to unsaturated slope stability analysis," Bulletin of Engineering Geology and the Environment, vol. 78, no. 4, pp. 2139-2150, 2019.

[28] B. Zhao, L. Zhang, and Z. Xia, "Effects of rainfall intensity and vegetation cover on erosion characteristics of a soil containing rock fragments slope," Advances in Civil Engineering, vol. 2019, p. 14, Article ID 7043428, 2019.

[29] C. Pan and Z. Shangguan, "Runoff hydraulic characteristics and sediment generation in sloped grassplots under simulated rainfall conditions," Journal of Hydrology, vol. 331, no. 1-2, pp. 178-185, 2006.

[30] H. Fang, L. Sun, and Z. Tang, "Effects of rainfall and slope on runoff, soil erosion and rill development: an experimental study using two loess soils," Hydrological Processes, vol. 29, no. 11, pp. 2649-2658, 2015.

[31] H. Chen, X. Zhang, M. Abla et al., "Effects of vegetation and rainfall types on surface runoff and soil erosion on steep slopes on the Loess Plateau, China," Catena, vol. 170, pp. 141-149, 2018.

[32] J. Arnaez, T. Lasanta, P. Ruiz-Flaño, and L. Ortigosa, "Factors affecting runoff and erosion under simulated rainfall in Mediterranean vineyards," Soil and Tillage Research, vol. 93, no. 2, pp. 324-334, 2007.

[33] D.-M. Sun, X.-M. Li, P. Feng, and Y.-G. Zang, "Stability analysis of unsaturated soil slope during rainfall infiltration using coupled liquid-gas-solid three-phase model," Water Science and Engineering, vol. 9, no. 3, pp. 183-194, 2016.

[34] K.-H. Yang, J. N. A. A. Thuo, V. D. A. Huynh, T. S. Nguyen, and F. H. M. Portelinha, "Numerical evaluation of reinforced slopes with various backfill-reinforcement-drainage systems subject to rainfall infiltration," Computers and Geotechnics, vol. 96, pp. 25-39, 2018.

[35] F. Cai and K. Ugai, "Numerical analysis of rainfall effects on slope stability," International Journal of Geomechanics, vol. 4, no. 2, pp. 69-78, 2004.

[36] L. M. Lee, N. Gofar, and H. Rahardjo, "A simple model for preliminary evaluation of rainfall-induced slope instability," Engineering Geology, vol. 108, no. 3-4, pp. 272-285, 2009.

[37] K. Mahmood, J. M. Kim, and M. Ashraf, "The effect of soil type on matric suction and stability of unsaturated slope under uniform rainfall," KSCE Journal of Civil Engineering, vol. 20, no. 4, pp. 1249-1299, 2016.

[38] S. Oh and N. Lu, "Slope stability analysis under unsaturated conditions: case studies of rainfall-induced failure of cut slopes,” Engineering Geology, vol. 184, pp. 96-103, 2015.

[39] N. Lu, B. Şener-Kaya, and A. Wayllace, "Analysis of rainfallinduced slope instability using a field of local factor of safety," Water Resources Research, vol. 48, no. 9, Article ID W09524, 2012.

[40] R. I. Borja and J. A. White, "Continuum deformation and stability analyses of a steep hillside slope under rainfall infiltration," Acta Geotechnica, vol. 5, no. 1, pp. 1-14, 2010.

[41] J. X. Liu, Y. T. Liu, and Q. J. Hu, "Stability of embankment slope subject to rainfall infiltration considering both runoffunderground seepage and fluid-solid coupling," Rock and Soil Mechanics, vol. 31, no. 3, pp. 903-910, 2010.

[42] S. E. Cho, "Infiltration analysis to assess the surficial stability of two-layered slopes considering rainfall characteristics," Engineering Geology, vol. 105, no. 1-2, pp. 32-43, 2009.

[43] G. Wang, W. Ye, and Y. Lv, "Loess geoheritage and geohazard protective measures at luochuan loess national geopark in NW China," Geoheritage, vol. 11, no. 3, pp. 1089-1100, 2019.

[44] H. Rahardjo, Y. Kim, N. Gofar, and A. Satyanaga, "Analyses and design of steep slope with GeoBarrier system (GBS) under heavy rainfall," Geotextiles and Geomembranes, vol. 48, no. 2, pp. 157-169, 2020.

[45] D. G. Fredlund, "Slope stability analysis incorporating the effect of soil suction," Slope Stability Research, vol. 4, pp. 113-144, 1987.

[46] L. Zeng, J. Liu, and J. Zhang, "“Effect of colluvial soil slope fracture's anisotropy characteristics on rainwater infiltration process," Advances in Civil Engineering, vol. 2018, p. 11, Article ID 7351628, 2018.

[47] X. B. Lu, T. L. Ye, X. H. Zhang, P. Cui, and K. H. Hu, "Experimental and numerical analysis on the responses of slope under rainfall," Natural Hazards, vol. 64, no. 1, pp. 887-902, 2012.

[48] X. Song and Y. Tan, "Experimental study on failure of temporary earthen slope triggered by intense rainfall," Engineering Failure Analysis, vol. 116, Article ID 104718, 2020. 
[49] A. Hojat, D. Arosio, and V. I. Ivanov, "Geoelectrical characterization and monitoring of slopes on a rainfall-triggered landslide simulator," Journal of Applied Geophysics, vol. 170, Article ID 103844, 2019.

[50] A. Chueasamat, T. Hori, H. Saito, T. Sato, and Y. Kohgo, "Experimental tests of slope failure due to rainfalls using $1 \mathrm{~g}$ physical slope models," Soils and Foundations, vol. 58, no. 2, pp. 290-305, 2018.

[51] A. Tohari, M. Nishigaki, and M. Komatsu, "Laboratory rainfall-induced slope failure with moisture content measurement," Journal of Geotechnical and Geoenvironmental Engineering, vol. 133, no. 5, pp. 575-587, 2007.

[52] J. Y. Park and Y. S. Song, "Laboratory experiment and numerical analysis on the precursory hydraulic process of rainfall-induced slope failure," Advances in Civil Engineering, vol. 2020, p. 12, Article ID 2717356, 2020.

[53] L. Brand, "The Pi theorem of dimensional analysis," Archive for Rational Mechanics and Analysis, vol. 1, no. 1, pp. 35-45, 1957.

[54] W. D. Curtis, J. D. Logan, and W. A. Parker, "Dimensional analysis and the pi theorem," Linear Algebra and Its Applications, vol. 47, pp. 117-126, 1982.

[55] K. Terzaghi, R. B. Peck, and G. Mesri, Soil Mechanics in Engineering Practice, John Wiley \& Sons, Hoboken, NJ, USA, 1996.

[56] L. Q. Li, Study on rainfall mechanical response and safety evaluation on soil slope along high-speed railway, Ph.D. thesis, Southwest Jiaotong University, Chengdu, Sichuan, 2013, in Chinese.

[57] S. C. Zhao, "Centrifugal model test of rainfall on soil slope," Master thesis, Southwest Jiaotong University, Chengdu, Sichuan, 2014, in Chinese.

[58] J. Tang, "In high fill slope stability analysis under the condition of heavy rainfall by panzhihua airport as an example," Master thesis, Chengdu University of Technology, Chengdu, Sichuan, 2014, in Chinese.

[59] H. Gvirtzman, E. Shalev, and O. Dahan, "Large-scale infiltration experiments into unsaturated stratified loess sediments: monitoring and modeling," Journal of Hydrology, vol. 349, no. 1-2, pp. 214-229, 2008.

[60] T. Carlà, R. Macciotta, M. Hendry et al., "Displacement of a landslide retaining wall and application of an enhanced failure forecasting approach," Landslides, vol. 15, no. 3, pp. 489-505, 2018.

[61] Fredlund and D. G. Rahardjo, Soil Mechanics for Unsaturated Soils, Wiley, Hoboken, NJ, USA, 1993.

[62] Z. Liu, J. Chen, and D. Li, "Calculation of active earth pressure against rigid retaining wall considering shear stress," Rock and Soil Mechanics, vol. 37, no. 9, pp. 2443-2450, 2016.

[63] J. P. Sahoo and R. Ganesh, "Active earth pressure on retaining walls with unsaturated soil backfill," in Proceedings of the 1st GeoMEast International Congress and Exhibition on Sustainable Civil Infrastructure, Ground Improvement and Earth Structure, pp. 1-19, Sharm EL Sheikh, Egypt, August 2017. 